Document downloaded from:

http://hdl.handle.net/10251/47588

This paper must be cited as:

Benajes Calvo, JV.; Novella Rosa, R.; De Lima Moradell, DA.; Tribotte, P.; Quechon, N.; Obernesser, P.; Dugue, V. (2013). Analysis of the combustion process, pollutant emissions and efficiency of an innovative 2-stroke HSDI engine designed for automotive applications. Applied Thermal Engineering. 58(1-2):181-193. doi:10.1016/j.applthermaleng.2013.03.050.

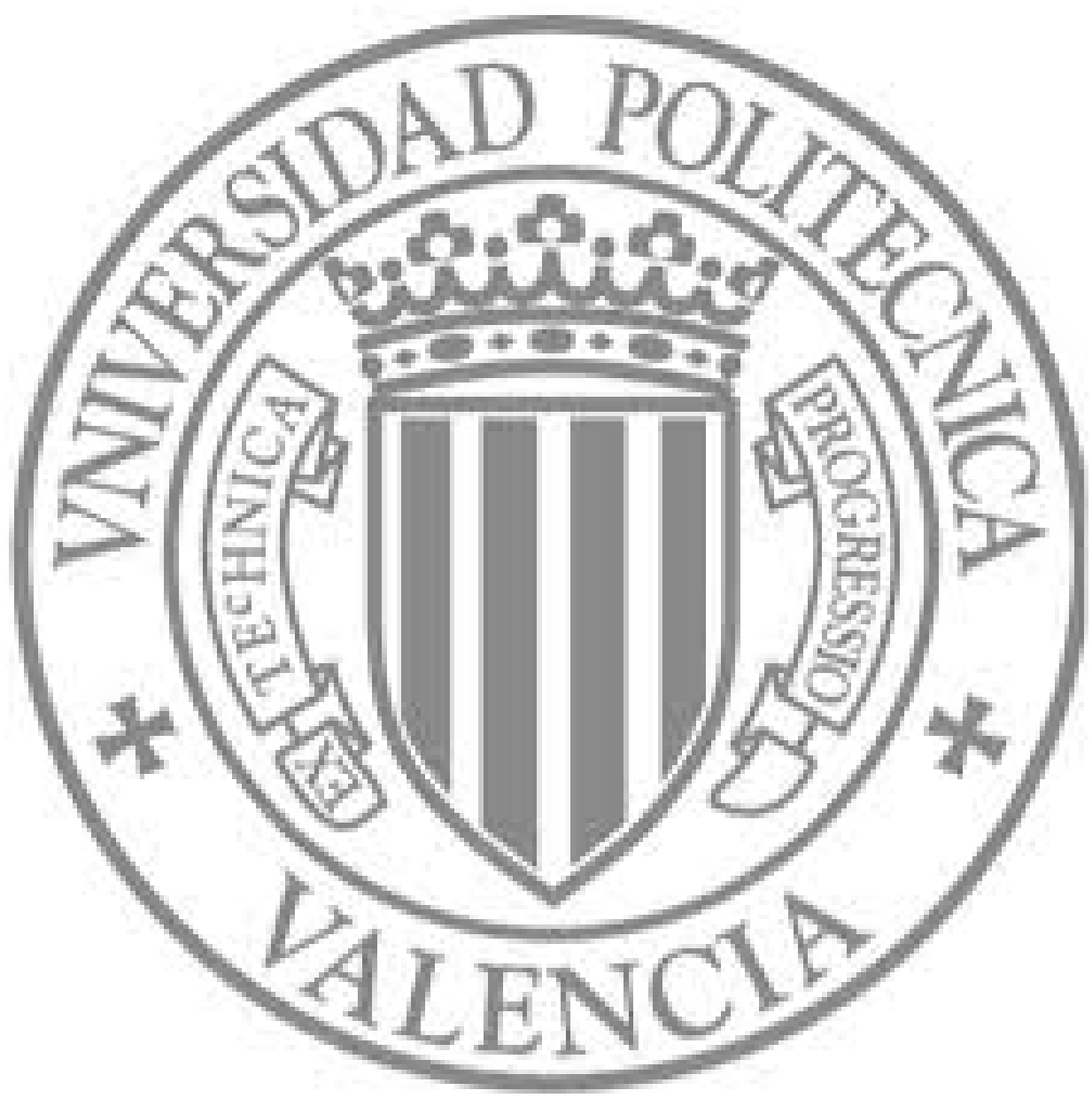

The final publication is available at

http://dx.doi.org/10.1016/j.applthermaleng.2013.03.050

Copyright Elsevier 


\title{
Analysis of the combustion process, pollutant emissions and efficiency of an innovative 2-stroke HSDI engine designed for automotive applications
}

\author{
Jesus Benajes, Ricardo Novella*, Daniela De Lima \\ CMT-Motores Térmicos \\ Universitat Politècnica de València \\ Camino de Vera $s / n, 46022$, Valencia (Spain) \\ Tel. (0034) 963877650 / Fax (0034) 963877659 \\ Pascal Tribotte, Nicolas Quechon, Philippe Obernesser and Vincent Dugue \\ Renault SAS \\ Rue du Golf 1, 78288, Guyancourt (France) \\ Tel. (0033) (0)1 76856904 / Fax (0034) (0)1 76857716
}

\begin{abstract}
On the last years engine researchers has been focused on improving engine efficiency in order to decrease $\mathrm{CO}_{2}$ emissions and fuel consumption, while fulfilling the increasingly stringent pollutant emissions regulations. In this framework, engine downsizing arises as a promising solution, and 2-stroke cycle operation offers the possibility of reducing the number of cylinders without incurring in NVH penalties.

An experimental investigation has been performed to evaluate the performance of a newly-designed poppet valves 2-stroke engine, in terms of finding the proper incylinder conditions to fulfill the emission limits in terms of $\mathrm{NO}_{\mathrm{X}}$ and soot, keeping competitive fuel consumption levels. Moreover, present research work aims to improve the existing knowledge about the gas exchange processes in a 2-stroke engine with poppet valves architecture, and its impact over the combustion conditions, final exhaust emissions levels and engine efficiency.

The experimental results confirm how this engine architecture presents high flexibility in terms of air management control to substantially affect the in-cylinder conditions. The in-cylinder oxygen concentration and density, which are the product of a given trapping ratio and delivered mass flow, were linked to pollutant emissions and performance by their impact on instantaneous adiabatic flame temperature and spray mixing conditions. After the optimization process, it was possible to minimize simultaneously $\mathrm{NO}_{\mathrm{X}}$, soot and indicated fuel consumption, without observing a critical trade-off between the pollutant emissions and the fuel consumption.
\end{abstract}

Keywords:

Diesel Engine, 2-Stroke Engine, Diffusion-Controlled Combustion, Pollutant Emissions, Engine Efficiency

\footnotetext{
${ }^{*}$ Corresponding author

Email: rinoro@mot.upv.es

Phone: (0034) 963877655 // Fax: (0034) 963877659
} 


\section{Introduction}

On the past years, development of HSDI diesel engines has been primarily driven by the reduction of exhaust emissions, imposed by increasingly stringent pollutant emissions regulations, especially in terms of $\mathrm{NO}_{\mathrm{X}}$ and soot emissions. Recently, research effort is being shifted towards the improvement of engine efficiency due to the need of decreasing $\mathrm{CO}_{2}$ emissions and also of meeting the expectations of costumers regarding fuel consumption.

In this frame, conventional mixing-controlled diesel combustion will continue to be an important source for both $\mathrm{NO}_{\mathrm{X}}$ and particulate matter emissions (traced by soot emissions), and major efforts in optimizing diesel engines are currently being focused on decreasing simultaneously these two pollutant emissions without increasing significantly their competitive fuel consumption. Previous research works on advanced combustion concepts with high degree of premixing and low oxygen concentration, such as HCCI [1], PCCI [2][3] and LTC [4] combustions, confirmed how it is possible to decrease down to near to zero values $\mathrm{NO}_{\mathrm{X}}$ and soot levels simultaneously [5]. Nevertheless, several technological drawbacks has not been yet solved, such as combustion noise [6], combustion phasing control [7][8] and high CO-HC emissions, among others, compromising the real application of these strategies in small passenger cars, particularly using diesel fuel.

Among the different technical approaches investigated to reduce fuel consumption and $\mathrm{CO}_{2}$ emissions, a promising solution consists of downsizing the diesel engine by reducing the engine displacement [9][10], which requires a high specific power output to maintain the expected performance and drivability [11][12]. However, heavily downsizing of diesel engines still presents some technical challenges ahead; mainly in terms of turbocharging systems [13], thermo mechanical resistance, high pressure/speed injection systems [14] and powertrain NVH [15][16].

An interesting alternative for extreme downsizing is taking advantage of the 2-stroke engine cycle, which doubles the firing events per crankshaft revolution, to reduce the number of cylinders without incurring in NVH penalties. Moreover, the need of more compact engines with higher power-to-weight ratios for small/economic passenger cars or as a range extenders for hybrid applications, recently revived the interest in investigating the 2-stroke operation in diesel HSDI engines [17][18]. 
The idea behind this new engine concept is to depart from a conventional HSDI diesel 4-stroke engine $\left(1460 \mathrm{~cm}^{3}, 4\right.$ cylinders) and implement a 2-stroke operation cycle to downsize the engine displacement by a factor of two, obtaining a 2-stroke engine (730 $\mathrm{cm}^{3}, 2$ cylinders) with equivalent NVH and similar torque response than the 4-stroke 4 cylinder engine. Cylinder-exhaust-ported engines and uniflow architectures were rejected for reliability and investment reasons, whereas the poppet valves architecture with scavenging loop offered several advantages in terms of durability, design and manufacturing, so it was chosen for this new engine concept regardless of its scavenging and trapping difficulties [17].

Then, the 2-stroke engine architecture investigated in this research work performs the gas exchange process through poppet valves placed on the cylinder head, and both intake and exhaust events are shorter and more overlapped compared to the 4-stroke cycle. Additionally, a positive pressure drop between the intake and exhaust ports, defined as $\Delta \mathrm{P}$, is mandatory over the complete range of engine speeds to allow the proper scavenging of the burnt gases and minimize the rate of internal gas recirculation (burnt gases which are not expelled out of the cylinder after the exhaust event). Advanced supercharging technology is required to achieve the expected high $\Delta \mathrm{P}$ ratios, as well as a variable valve timing system for controlling the camshafts phasing and overlap period between the intake and exhaust phases. The first stages of conception, focused on the calculation and pre-design of the air loop system and the combustion chamber geometry of this 2-stroke concept engine, has been described in detail in two previous publications, along with some preliminary experimental results [17][18].

The control of the air management and in-cylinder conditions on this type of engine architecture is fundamental for both combustion development and final engine cycle efficiency, increasing significantly the complexity of engine optimization and calibration; mainly because there are multiple air management actuation levers to be controlled aside from the usual injection settings. Therefore, it is important to establish a proper testing methodology when optimizing the combustion/emissions characteristics of this 2-stroke engine architecture [19][20].

Departing from this background, this research has been focused on the evaluation of this newly-designed 2-stroke engine concept considering air management, combustion, pollutant emissions and performance. Additionally, this research work aims to improve 
the understanding of the relation between the gas exchange process and the most important combustion-related parameters, which will determine the final exhaust emissions levels and engine fuel consumption. Since the in-cylinder conditions are highly sensitive to air management settings, a DOE optimization methodology has been proposed to establish the real potential of this engine architecture in terms of emissions and fuel consumption; keeping in this first stage of engine evaluation the emissions limits demanded by the EU5 legislation to gain the knowledge required for developing future strategies to switch towards future EU6 emission levels.

\section{Experimental setup}

\subsection{Engine architecture and hardware}

The experimental activities were performed on a single-cylinder research version of this 2-stroke HSDI diesel engine prototype, with the same architecture and design than the two cylinder engine. As a reference, Table 1 contains the main engine geometrical characteristics of this single-cylinder 2-stroke engine.

The cylinder head and combustion chamber geometry, shown in Fig. 1, were completely adapted to ensure a suitable in-cylinder flow pattern during 2-stroke operation, in order to optimize the scavenging of burnt gases and to reduce the short-circuit losses of fresh air going directly from the intake into the exhaust ports. The cylinder head geometry presents a staged roof for baffling the flow of air between the intake and exhaust valves, forcing the air to follow the path of the cylinder wall towards the bottom of the cylinder. This geometry provides the best compromise between scavenging efficiency, acceptable permeability, and convenient combustion chamber geometry [17].

The engine is equipped with an hydraulic cam-driven Variable Valve Timing system, allowing a flexibility of 30 degrees on both intake and exhaust valve timings independently from the mechanical cam timing. The flexibility of the VVT system is shown in Fig. 2, where the intake and exhaust cam lift laws have been included for the nominal phasing angle and also for the two extreme, minimum and maximum, timing positions. Then, the effective compression ratio, overlap between intake and exhaust, and effective expansion ratio can be modified by adjusting the valve timing angles. The optimum intake/exhaust camshaft configuration for this engine was previously defined 
experimentally by testing different opening durations and maximum lifts at a medium load/medium speed point; the selected camshaft definition is shown in Table 1.

The injection system is a prototype which allows a maximum rail pressure of 1800 bar. The injector is equipped with a 8 holes nozzle, with a hole diameter of $90 \mu \mathrm{m}$ to assure good atomization of the fuel and also to enhance the physical mixing process, and a conventional spray cone angle of $155^{\circ}$. The match between the optimum injector geometry and the piston bowl shape was obtained with 3D CFD calculations, and was confirmed with experimental data obtained on the single-cylinder engine. The injection system performance was validated by measuring the total mass flow rate and the sprays momentum flux in dedicated test rigs [21][22].

The trapping ratio or trapping efficiency is defined as the mass of delivered charge that has been trapped in the cylinder before combustion divided by the mass of delivered charge supplied to the cylinder (fresh air plus EGR) for one engine cycle. The trapping efficiency is used to characterize the use of the fresh gases delivered to the cylinder and indirectly to know the fraction of short-circuited gas.

The trapping ratio is experimentally measured using a tracer gas method [23][24], thereby, a controlled quantity of $\mathrm{CH}_{4}$ (tracer gas) is homogeneously injected in the intake flow and the concentration of $\mathrm{CH}_{4}$ is measured at the intake and also at the exhaust manifolds. Then, assuming that all the $\mathrm{CH}_{4}$ trapped in the cylinder will burn completely during combustion, an accurate estimation of the short-circuited mass from the intake flowing directly to the exhaust is performed by means of a set of mass balances in the intake, exhaust and in-cylinder gases.

The internal gas recirculation (IGR) ratio is then defined as the fraction of residual gases retained from the previous combustion cycle in the total trapped mass in the cylinder. Consequently, the total trapped mass in the cylinder is given by the addition of the delivered charge mass finally retained in the cylinder after the IVC ( $\left.\mathrm{Q}_{\text {del_trapped }}\right)$ and the mass of residual gases (IGR) which were not exhausted from the previous combustion cycle. Finally, the effective or trapped air/fuel ratio is calculated from the mass of usable air available in the trapped charge, excluding the air present in the IGR since it is not really usable, divided by the injected fuel mass.

The IGR ratio and the total trapped mass are estimated using simplified thermodynamic calculations. This estimation is based on an enthalpy balance, where the enthalpy of the 
total trapped mass at the IVC equals to the enthalpy of the residual mass plus the enthalpy of the intake delivered trapped mass (fresh air plus external EGR), both estimated also at the IVC.

Since the 2-cylinder engine concept presents a double stage supercharging system, with a mechanical volumetric charger set downstream to a WG turbocharger [17][18], it is valuable to estimate the compression work needed to achieve the required intake boost pressure by means of thermodynamic calculations, to obtain an approximation of the expected "or equivalent" indicated specific fuel consumption (isf corr $_{\text {) }}$ ) which could be obtained on the 2-cylinder engine. This correction is useful for assuring feasible operating conditions on the 2-cylinder engine, avoiding conditions out of the scope due to very high pressure ratios or extremely high air flow rates.

\section{2. $\quad$ Test cell characteristics}

The engine was assembled into a fully instrumented test cell according to the scheme shown in Fig. 3. The engine is fed with the compressed air (oil and water-free) provided by an external compressor in order to simulate boost conditions. The exhaust backpressure produced by the turbine is reproduced and controlled by means of a throttle valve placed in the exhaust line after the exhaust settling chamber. The experimental facility also includes a low pressure EGR system, designed to provide arbitrary levels of cooled EGR even at very high intake boost pressures.

Water and oil cooling circuits are also independent from the engine, and temperatures are strictly controlled and monitored during all the experimental tests. The fuel consumption of the engine is measured with a gravimetric dynamic fuel meter.

Pollutant emissions from the engine are sampled close to the exhaust settling chamber and routed to a state-of-the-art gas analyzer by a heated pipe to ensure gas temperatures above $150^{\circ} \mathrm{C}$. Measurements of $\mathrm{O}_{2}, \mathrm{CO}, \mathrm{CO}_{2}, \mathrm{HC}, \mathrm{NO}_{\mathrm{X}}, \mathrm{N}_{2} \mathrm{O}$, and EGR rate are performed for all the tests. Exhaust smoke is measured by an AVL 415 Smokemeter to obtain the smoke number (FSN). In addition, a dedicated $\mathrm{CH}_{4}$ analyzer is used to trace both intake and exhaust $\mathrm{CH}_{4}$ concentrations when performing trapping ratio measurement in each engine operating point.

Most relevant averaged test cell and engine parameters, pollutant emissions, and high frequency instantaneous signals are recorded using a dedicated data acquisition system. The high frequency signals are acquired using an oscilloscope, and synchronized with 
an optical angular encoder with a resolution of $0.2 \mathrm{cad}$. The cylinder pressure is measured using a piezoelectric sensor, while a different piezorresistive pressure sensor is placed at the cylinder liner close to the BDC to reference the piezoelectric sensor pressure signal.

The most relevant parameters related to the combustion process, such as the indicated mean effective pressure (IMEP), combustion noise, combustion phasing, maximum cylinder pressure, pressure gradient, combustion stability and rate of heat release (RoHR) are calculated from the cylinder pressure by an in-house combustion analysis software ("CALMEC") [25][26].

\section{Methodology}

In order to evaluate the performance of this innovative 2-stroke HSDI poppet-valves engine concept on a strictly controlled test environment, it was necessary to define a fast and efficient experimental test methodology, which was based on isolating the optimization process of the air management parameters from that of the injection parameters. This optimization is focused on finding the most suitable in-cylinder conditions necessary to fulfill the emission limits, especially in terms of $\mathrm{NO}_{\mathrm{X}}$ and soot, while minimizing the fuel consumption as much as possible. Based on this objective, a dedicate test campaign for studying the air management characteristics was designed in order to easily identify the cause/effect relations of the air management parameters over the in-cylinder conditions, and consequently over combustion development and exhaust emissions. A Design of Experiment (DOE) methodology is proposed in order to find the best settings for the air management related parameters for a given engine operating condition. A Central Composite Design (CCD) was selected to build the test plan since this design allows modeling the responses using a quadratic equation, taking into account all possible second order interactions between the factors.

The main air management settings chosen as factors for the air management DOE are the EGR rate, intake pressure, pressure difference between intake and exhaust $(\Delta \mathrm{P})$ and valve overlap duration. The intake valve timing was kept constant at a value previously obtained by a parametric optimization, so the exhaust valve timing is defined consequently depending on the desired valve overlap duration.

The engine operating condition chosen for this experimental test campaign, corresponds with a medium speed (1500 rpm) and medium load (5.5 bar of IMEP) 
point, and the most relevant experimental conditions as well as the expected targets in terms of exhaust emissions and noise are described in Table 2. The ranges of variation for the air management settings included as factors in the DOE are included in Table 3, and they were selected based on preliminary calculations with a 1D wave action model combined with fast screening parametric tests performed on the engine. The tests were all performed with a constant injection pressure of 900 bar and with 2 injection events, one small pilot injection of $2.2 \mathrm{mg} / \mathrm{st}$ placed at $-19 \mathrm{cad}$ aTDC, and a main injection, for which the injected quantity and timing (SoI) are adjusted to maintain a constant value of IMEP of 5.5 bar and a CA50 phased at 3 cad aTDC.

The pollutant emissions and noise limits imposed along this initial evaluation of the engine concept corresponds to the Euro 5 levels measured on a 4-stroke engine with equivalent characteristics in terms of unitary displacement and geometry.

\section{Results and discussion}

\subsection{DOE validation}

The results obtained after performing 36 points of the test matrix included in the design of experiments, are useful for providing an overview of the behavior of several measured engine responses, and their relations with the four selected air management factors. Table 4 shows the most important quality indicators to check the fit of the quadratic mathematical model for each measured or calculated response.

The regression coefficient is very close to 1 ("perfect fit") in the case of all the responses directly measured on the engine, as in the case of trapping ratio, delivered fresh air, $\mathrm{NO}_{\mathrm{X}}$ and soot emissions. Concerning fuel consumption, since the measured range of variation was small, around 5\%, it was more difficult to assure a perfect fit due to some small dispersion, less than $1 \%$, on the measured central points of the DOE. Estimated parameters such as in-cylinder richness, oxygen concentration at the IVC, adiabatic flame temperatures and spray mixing capacity have slightly lower, but still acceptable, regression coefficients than the directly measured responses, since they are derived from the measured responses through thermodynamic calculations or combustion analysis calculations. In any case, the statistical models are well fitted to the experimental data and they are useful to observe important trends between the air management parameters and several engine responses with a high degree of confidence. 
Moreover, the use of the statistical model of the responses will not only help understanding the physical phenomena related to air management and combustion conditions but also will provide the guidelines for the optimization process in terms of fuel consumption and exhaust emissions.

\subsection{Air management process}

Two stroke poppet valves architecture inherently exhibits low trapping efficiencies compared to four stroke engines, due to the required positive pressure difference between the intake and exhaust, the long overlap duration, and proximity between intake and exhaust valves (even with masking on the intake); making very difficult to balance the air charging of the cylinder with the short-circuit losses, while simultaneously ensuring proper scavenging of the burnt gases. The experimental results showed how all DOE measured points were comprised inside a range of variation from $60 \%$ to $80 \%$ of trapping ratio, which was subsequently limited along the optimization process to $65 \%$ to $80 \%$, in order to avoid extremely low values of trapping ratios, which are not feasible for the final engine application.

Concerning the IGR ratio, previous studies showed how decreasing trapping efficiency improved the scavenging of burnt gases out of the cylinder, until reaching a practical lower limit, where it was not possible to decrease furthermore the IGR [17]. In this research, the ranges for the air management parameters were pre-selected in advance to assure the lowest percentage of IGR ratio as possible. Additionally, since it is necessary to introduce high levels of EGR to achieve the $\mathrm{NO}_{\mathrm{X}}$ limit, the ranges chosen for the overlap, $\Delta \mathrm{P}$ and intake pressure were slightly overestimated towards high air flow rates and medium-to-low trapping ratios. Within these ranges, the IGR ratio remained approximately constant for all the measured points at around $30 \%$. Nevertheless, even operating with lower trapping efficiencies and higher residual gas fraction than in 4stroke engines, suitable in-cylinder conditions can be achieved to assure high combustion efficiencies and competitive indicated efficiencies comparable to those obtained in 4-stroke engines.

Fig. 4 shows the relation between trapping ratio and the delivered charge mass (fresh air plus EGR) supplied to the cylinder with $\Delta$ P, Fig. 4.a, and overlap, Fig. 4.b. According to these figures, due to the reduced cylinder head permeability in the intake side caused by the masking surface, $\Delta \mathrm{P}$ needs to be increased to attain high $\mathrm{Q}_{\text {delivered }}$ levels, but the 
overlap should be decreased to keep suitable levels of trapping ratio, since the shortcircuited mass flow flowing from the intake to the exhaust depends mainly on the width of the valve overlap. In fact, the grading observed in Fig. 4 confirms how the best combination of $\mathrm{Q}_{\text {delivered }}, 40 \mathrm{~kg} / \mathrm{h}$, and trapping ratio, $70 \%$, is attained at the highest $\Delta \mathrm{P}$ and the narrower valve overlap. Intake pressure has some effect on trapping ratio, but much lower than in the case of $\Delta \mathrm{P}$ and valve overlap, furthermore, the EGR rate has a very small effect on trapping ratio. Finally, results confirm how the trapping ratio will result from the simultaneous combination of the four factors, being $\Delta \mathrm{P}$ and overlap the two most influential factors.

Focusing on the in-cylinder conditions at the intake valve closing, Fig. 5.a shows how the highest levels of $\mathrm{YO}_{2}$ IVC (16\%) are attained for trapping ratios ranging between $65 \%$ and $75 \%$ while the lowest levels (13\%) are attained for high trapping ratios, where $\mathrm{Q}_{\text {delivered }}$ is compromised. Additionally, the reduction in $\mathrm{YO}_{2}$ IVC directly caused by the EGR explains the different values of $\mathrm{YO}_{2}$ IVC observed for the same combination of delivered mass flow and trapping ratio.

The effective in-cylinder equivalence ratio ( $\phi_{-}$cyl_eff) is calculated from the stoichiometric air/fuel ratio, the injected fuel quantity and the usable air available in the trapped charge. It is also important to remark that the injected fuel quantity was adjusted along the points of the DOE for keeping constant the IMEP value, compensating the differences in cycle and combustion efficiencies, which has a direct impact on the $\phi_{-}$cyl_eff. Fig. 5.b illustrates how in general, $\phi_{-}$cyl_eff ranges from 0.6 to 0.8 and follows the usual opposite trend compared to $\mathrm{YO}_{2}$ IVC, so those points with low $\mathrm{YO}_{2}$ IVC have high $\phi_{-}$cyl_eff levels.

\subsection{Combustion process}

The combustion process on this type of two stroke poppet valves architecture is highly sensitive to the in-cylinder conditions obtained at each determined combination of air management settings. In the case of the maximum cylinder pressure, it ranges from 73 bar to 83 bar within the points of the DOE and it is phased around 4.0 to 5.5 cad aTDC; moreover, it is determined by the total trapped mass and by the cylinder absolute pressure at the IVC which is controlled by the scavenging process and specially by the valve overlap. The maximum pressure gradient ranges from 6 to $9 \mathrm{bar} / \mathrm{cad}$ and it is phased from -3 cad aTDC to 2 cad aTDC, while combustion stability represented by the 
IMEP covariance remains under $1.5 \%$ for all the points, which are conventional levels for diffusive diesel combustion.

The ignition delay of the main injection, the peak of the RoHR, the maximum pressure gradient, and the combustion noise are shown in Fig. 6 and Fig. 7 as function of the $\mathrm{YO}_{2} \mathrm{IVC}$ and the in-cylinder mean gas temperature at the SoI of the pilot injection. The points with low oxygen concentration at IVC and low mean gas temperatures along the injection process has longer ignition delays as expected, resulting in a very rapid and sharp premixed combustion phase with large pressure gradients which are responsible for higher combustion noise. On the contrary, when the ignition delays is decreased by increasing the YO2 IVC or by increasing the temperature along injection, smother combustion profiles with more predominant diffusive flame phase were observed, exhibiting lower peaks of the RoHR, lower pressure gradients and lower noise.

The instantaneous adiabatic flame temperature at the stoichiometric flame location is used to describe qualitatively the $\mathrm{NO}_{\mathrm{X}}$ formation and soot oxidation along the combustion process. The adiabatic flame temperature $\left(\mathrm{T}_{\mathrm{ad}}\right)$ is estimated through an iterative calculation taking into account 13 species in the reaction following the scheme proposed by Way [27]. The thermal mechanisms involved in the formation of nitrogen oxides $\left(\mathrm{NO}_{\mathrm{x}}\right)$ are greatly chemically controlled and determined by combustion temperature and oxygen availability at the periphery of the flame [28][29]; therefore, the maximum adiabatic flame temperature is a good tracer on the formation of nitrogen oxides.

Fig. 8.a illustrates the maximum adiabatic flame temperature $\left(\mathrm{T}_{\text {ad_max }}\right)$ distribution as a function of $\mathrm{YO}_{2}$ IVC and $\phi_{-}$cyl_eff. It clearly shows how decreasing $\mathrm{YO}_{2}$ IVC will decrease $\mathrm{T}_{\text {ad_max }}$, and consequently $\mathrm{NO}_{\mathrm{X}}$ formation, due to the dilution effect of the inert exhaust gas inside the combustion chamber, but as a counterpart $\phi_{\text {_cyl_eff }}$ increases.

The late diffusive stage of combustion, between the EoI and the EoC, is fundamental for defining the final soot emissions level, because the soot oxidation process is substantially slowed down due to the fast decrease of in-cylinder gas temperature and density. The soot formed inside the flame is oxidized outside the flame around the stoichiometric zone, by the attack of $\mathrm{OH}$-radicals which are thought to be the major mechanism responsible for soot oxidation in near stoichiometric conditions as in the case of diffusion flames [30]. Therefore, high local temperatures at the late stages of 
combustion and presence of oxygen are mandatory to increase the rate of formation of OH-radicals and enhance the chemical process of soot oxidation [31][32]. The adiabatic flame temperature at the point of $80 \%$ of fuel mass burnt fraction $\left(\mathrm{T}_{\text {ad_ } 80 \% \mathrm{MBF}}\right)$ has been used by various authors to describe the late soot oxidation process [33]-[35], so it was selected to be representative of the late oxidation temperature.

Fig. 8.b shows how $\mathrm{T}_{\text {ad_80\%MBF }}$ follows a similar trend than $\mathrm{T}_{\text {ad_max }}$, so reducing the maximum adiabatic temperature by decreasing the $\mathrm{YO}_{2}$ IVC leads to an equivalent reduction in the temperature at the final stages of combustion, consequently punishing the soot oxidation process as expected. Note how below certain $\mathrm{YO}_{2}$ IVC level, approximately $15 \%$, the trend followed by $\mathrm{T}_{\text {ad_ }} 80 \% \mathrm{MBF}$ in Fig. $8 . \mathrm{b}$ is not vertical since the effect of the mixing rate of the fuel spray over the $\mathrm{T}_{\text {ad_80\%MBF }}$ starts to gain relevance.

Focusing on the mixing process, in diesel sprays it is ruled mainly by the injection parameters, the fuel properties and the in-cylinder conditions, specifically oxygen concentration and gas density. The characteristic time required for a fuel particle injected in a steady state non-reactive gas jet to reach the stoichiometric conditions is given following the equation (1) [36]:

$$
t_{\text {mix }}=K_{1}\left[(A / F)_{s t} \cdot \frac{Y O_{2} a t m}{Y O_{2}}\right]^{2} \cdot \frac{\mathscr{\rho}_{0}}{u_{0}} \cdot \sqrt{\frac{\rho_{f}}{\rho}}
$$

Where $K_{l}$ is a constant that depends on the engine and its configuration, $(A / F)_{s t}$ is the stoichiometric air-fuel ratio, $\mathrm{YO}_{2}$ atm and $\mathrm{YO}_{2}$ corresponds to the oxygen mass concentration at ambient conditions and inside the cylinder, $u_{0}$ is the injection velocity, $\emptyset_{0}$ the injector nozzle diameter and $\rho_{f}$ and $\rho$ are respectively the density of the fuel and the density of the gas inside the cylinder.

Then, the mixing capacity is defined as the inverse of the characteristic mixing time, and it serves as a good indicator of the mixing rate of the spray; for which it has been linked to the late soot oxidation in previous research works [32]. For this research in particular, since the injection velocity and fuel properties were kept constant along the tests, it is possible to redefine the mixing capacity [36] and re-write the expression derived from equation (1) as follow:

$$
\text { Mixing Capacity } \propto \frac{1}{t_{\text {mix }}} \propto \sqrt{\mathrm{YO}_{2}{ }^{\circ} \rho}
$$


The mixing capacity was calculated at the time where $80 \%$ of the fuel has been burnt $\left(\mathrm{ACT}^{-1}{ }_{80 \% \mathrm{MBF}}\right.$ ), to be representative of the mixing conditions at the late diffusive combustion stage, which is crucial for the late soot oxidation process. Fig. 9 presents the relative mixing capacity or $\mathrm{ACT}^{-1}{ }_{80 \% \mathrm{MBF}}$ as function of $\mathrm{YO}_{2}$ IVC and $\phi_{-}$cyl_eff, note that the points are presented as the percentage of improvement in mixing rate compared to the point which has the "worst/lowest" mixing capacity. The points with high $\mathrm{YO}_{2} \mathrm{IVC}$ and low $\phi_{-}$cyl_eff have the highest mixing capacity, which results in an improvement in mixing conditions of around $40 \%$ compared to the worst points; the opposite situation is observed for the points with low $\mathrm{YO}_{2}$ IVC and high $\phi_{-}$cyl_eff which presents the lowest mixing capacity due to the worsened mixing conditions. It is worth to recall that the mixing capacity depends on both $\mathrm{YO}_{2}$ and gas density, so the final mixing rate will account for the effects of these two parameters. Then, at a constant $\phi_{-}$cyl_eff of 0.75 , lower oxygen concentration does not implies lower mixing rate as expected, on the contrary, the mixing capacity increases as a reflect of an increase in gas density due to higher delivered trapped mass. As it confirmed by Fig. 9.b, the mixing capacity increases with higher delivered trapped mass $\left(\mathrm{Q}_{\text {del_trapped }}\right)$ since in this situation the incylinder density is also higher, and also when combustion ends earlier in the cycle (represented with the CA90), so the final stage of combustion occurs at enhanced incylinder conditions.

\subsection{Exhaust emissions and performance}

The smoke- $\mathrm{NO}_{\mathrm{X}}$ trade-off will be used to present the range of variation of the most important emissions along the points of the DOE, and to link the final emissions levels to the combustion process. $\mathrm{NO}_{\mathrm{X}}$ emissions ranges from $2.5 \mathrm{mg} / \mathrm{s}$ to $0.6 \mathrm{mg} / \mathrm{s}$ along the points of the DOE and smoke level ranges from 0.2 FSN to $2.5 \mathrm{FSN}$; while the optimization targets established by EU5 were $0.75 \mathrm{mg} / \mathrm{s}$ and 0.56 FNS respectively. CO emissions are sharply increased (up to $9 \mathrm{mg} / \mathrm{s}$ ) well above the required target $(4.4 \mathrm{mg} / \mathrm{s}$ ) when $\mathrm{NO}_{\mathrm{X}}$ emissions are decreased, following the same trend as soot emissions, as shown in Fig. 10; while HC emissions are below the target $(0.65 \mathrm{mg} / \mathrm{s})$ in all the points; which is finally translated in combustion efficiencies above $99 \%$ for all the range of the DOE. 
Fig. 11 shows both $\mathrm{T}_{\text {ad_max }}$ and $\mathrm{T}_{\text {ad__80\%MBF }}$ placed on the smoke- $\mathrm{NO}_{\mathrm{X}}$ trade off. The points with high $\mathrm{T}_{\text {ad_max }}$, which are those points with high $\mathrm{YO}_{2}$ IVC and low $\phi_{-}$cyl_eff, have a high rate of formation of $\mathrm{NO}_{\mathrm{X}}$ emissions as explained before, and additionally, since $\mathrm{T}_{\text {ad_ }} 80 \% \mathrm{MBF}$ is also high, the late soot oxidation process is enhanced resulting in low levels of soot emissions. Decreasing $T_{\text {ad_max }}$ by introducing EGR or affecting the air management conditions leads to a consequent decrease on $\mathrm{T}_{\text {ad_80\% }}$ MBF, reason why thermal $\mathrm{NO}_{\mathrm{X}}$ rate of formation is slowed down together with the oxidation soot rate. The best compromise on the smoke-NOX $\mathrm{NO}_{\mathrm{X}}$ trade off, are those points where $\mathrm{T}_{\mathrm{ad} \_m a x}$ is relatively low but the mixing conditions are enhanced, favoring the rate of combustion and the late soot oxidation process, as shown in Fig. 9, resulting in low soot levels. This is shown in Fig. 12, where the percentage of improvement in $\mathrm{ACT}^{-1}$ 80\% MBF confirms how the points with simultaneous low $\mathrm{NO}_{\mathrm{X}}$ and low smoke level have around $25 \%$ higher mixing capacity compared to the points with low $\mathrm{NO}_{\mathrm{X}}$ but high smoke emissions. Additionally, Fig. 10 shows how CO emissions, which are also controlled by the late oxidation processes, followed the same trend as soot/smoke emissions. This result evidences the direct relation between the conditions at the final stages of combustion $\left(\mathrm{T}_{\text {ad_80\% }} \mathrm{MBF}\right.$ and $\left.\mathrm{ACT}^{-1} 80 \% \mathrm{MBF}\right)$, the oxidation processes and the final $\mathrm{CO}$ and soot emissions level.

In terms of engine performance, Fig. 13.a illustrates how the combustion related parameters are directly linked with both exhaust emissions and engine efficiency. The points with high $\mathrm{T}_{\text {ad_max }}$ and enhanced mixing process have low smoke emissions, medium-to-high $\mathrm{NO}_{\mathrm{X}}$ levels and low isfc, mainly because combustion takes place in a favorable environment for the fuel-energy conversion processes, where the fresh air trapped mass flow is high and $\mathrm{YO}_{2}$ IVC is high as well, while $\phi_{-}$cyl_eff is low.

The corrected indicated specific fuel consumption expected at the two cylinder engine, (isfe $\mathrm{corr}_{\text {( })}$ is shown in Fig. 13.b, and the points with low smoke and high $\mathrm{NO}_{\mathrm{X}}$ emissions, which previously had the lowest isfc, now presents higher corrected isfe corr $_{\text {, after }}$ considering the compression work needed to achieve the intake pressure and the required delivered air flow rate. To decrease isfe $\mathrm{corr}_{\text {it }}$ it is necessary to find a good combination of initially low isfc with a medium-to-low intake air flow rate which does not require too high compression work. In the case of points with high smoke emissions, even when the delivered intake flow rate is lower (high $\phi_{-}$cyl_eff and low $\mathrm{YO}_{2}$ 
IVC) the worsened combustion conditions leads to a higher initial indicated fuel consumption, therefore, the gain in compression work does not compensate the losses in engine efficiency.

The objective of the final stage in the DOE analysis is to find the best trade-off between exhaust emissions, referring to $\mathrm{NO}_{\mathrm{X}}$ and smoke emissions mostly, and indicated fuel consumption. Afterwards, an optimum point is selected considering the air management settings and measured experimentally on the engine, to check the accuracy on the prediction performed with the statistical model for the selected responses.

\subsection{Optimization of emissions and performance}

The aim of the optimization process is to find the best possible combination between $\mathrm{NO}_{\mathrm{X}} /$ soot emissions and isfc or isfc $\mathrm{c}_{\text {corr }}$ within the ranges of the DOE. A merit or objective function, identified as MF and shown in equation (3), has been selected for this purpose and it requires a target or objective value for each response, and specific adjustment coefficients to place more emphasis on satisfying one particular response among the others. This function allows for each combination of input parameters to be compared based on the desired target or objectives for the responses. Larger values of the merit function correspond to those combinations of the responses that better satisfy the desired objectives [37].

$$
M F=\frac{1000-\sum_{i}\left(\alpha_{i}\right)}{\sum_{i}\left(\alpha_{i} e^{-\beta_{i} \frac{R V-O V i}{O V i}}\right)}
$$

In equation (3) $\alpha$ and $\beta$ are adjustment coefficients to favor the optimization of a desired response, $R V$ is the response value, $O V$ is the objective or target value for the response and $i$ is the selected response.

Two merit functions were calculated to find the best combination between $\mathrm{NO}_{\mathrm{X}}$, soot and isfc $\left(\mathrm{MF}_{\mathrm{NO} \text {, soot, isfc }}\right.$ in Fig. 14.a) and also between $\mathrm{NO}_{\mathrm{X}}$, soot and isfc corr $\left(\mathrm{MF}_{\mathrm{NOx}, \text { soot,isfcorr }}\right.$ in Fig. 14.b). The same weight or emphasis on the optimization was applied for the 3 responses; however, in the case of emissions the percentage of $\mathrm{NO}_{\mathrm{X}}$ and soot variation is much higher within the space of the DOE than in the case of fuel consumption.

From Fig. 14.a, it is clear how the maximum of the merit function appears always at the best compromise between soot and $\mathrm{NO}_{\mathrm{X}}$ emissions, which means that it is possible to 
minimize simultaneously $\mathrm{NO}_{\mathrm{X}}$, soot and indicated fuel consumption without the existence of a trade-off between emissions and consumption. Moreover, in the case of isf $c_{\text {corr }}$, even when the optimum point for minimum $\mathrm{NO}_{\mathrm{X}}$ and minimum soot does not corresponds to the optimum for isfc corr previously observed in Fig. 13.b, the simultaneous combination between the three responses shown in Fig. 14.b corresponds again with the same corner of the $\mathrm{NO}_{\mathrm{X}}$-soot trade off, being the best possible combination of the three responses since it maximizes the merit function. Then, it is possible to optimize $\mathrm{NO}_{\mathrm{X}}$, soot and engine isfc simultaneously, increasing isfc corr by less than $5 \%$.

Finally, this optimization methodology and results were validated by measuring the two optimums experimentally on the engine. Table 5 shows the error between the observed and predicted values for the two different optimum points obtained along the optimization process. These results confirm how the percentage of error between the predicted and measured responses is extremely low, below $2 \%$, for almost every response and only the smoke emissions differs by $5 \%$. Thus, it has been proven that the testing methodology, the statistical analysis and the optimization criteria have performed with high accuracy, providing the main guidelines to find the optimum operating conditions for achieving the expected optimization objectives. Finally, the most interesting measured responses obtained at the optimum point $\# 2$ are presented below in Table 6 .

During the statistical analysis and optimization process of the DOE, it has been demonstrated how the air management conditions have an important impact on the combustion and emissions formation processes, on this type of 2-stroke engine architecture. Nevertheless, even with an intrinsic inefficient architecture for the scavenging process, it is possible to operate with the inherently low trapping efficiencies and high amount of residuals, to achieve the proper in-cylinder conditions required to provide a suitable combustion process with high combustion efficiencies and competitive indicated fuel consumption. Table 6 shows how the concept engine performs at the selected optimum point \#2 after concluding the optimization process. The engine operates with a relatively low trapping efficiency of $68 \%$, has a $36 \%$ of IGR rate and $\phi_{-}$cyl_eff equal to 0.7 when introducing $35 \%$ of EGR. The combustion develops very high efficiency (99\%) and emissions levels are very close to the targets with more 
competitive indicated efficiency (46\%) than the equivalent 4-stroke engine (44\%) at the same load/speed combination. The final soot and $\mathrm{NO}_{\mathrm{X}}$ levels are very close to the expected EU5 targets without performing the fine-tuning of the injection settings.

\section{Conclusions}

The present research has been focused on evaluating the performance of a newlydesigned poppet valves 2-stroke engine in terms of finding the proper in-cylinder conditions necessary to fulfill the emission limits while keeping competitive fuel consumption. The engine architecture proved its potential to have high flexibility in terms of air management control, valve timing, EGR and intake boosting levels to substantially affect the in-cylinder conditions, and consequently the combustion development which determines final emissions level and indicated efficiency. The following main conclusions can be extracted from this research work:

- The minimum effective in-cylinder equivalence ratio ( $\phi_{-}$cyl_eff $)$, is obtained at the point with higher delivered trapped mass $\left(\mathrm{Q}_{\text {del_trapped }}\right)$, which appears as the product between the trapping ratio and the total delivered flow ( $\left.\mathrm{Q}_{\text {delivered }}\right)$. The two most influential factors controlling the delivered trapped mass are the pressure drop $(\Delta \mathrm{P})$ and valve overlap. The best combination of trapping ratio and $\mathrm{Q}_{\mathrm{del} \_ \text {trapped }}$ is obtained with the highest values of $\Delta \mathrm{P}$ but with the lowest values of valves overlap.

- Low $\mathrm{NO}_{\mathrm{X}}$ emissions levels are attainable by reducing YO2 IVC and then, $\mathrm{T}_{\text {ad_max }}$ along the combustion process. In this 2-stroke engine, the YO2 IVC can be easily controlled by introducing external EGR, but also by affecting the air management conditions. However, reducing $\mathrm{T}_{\text {ad_max }}$ by decreasing the oxygen concentration without compensating with higher in-cylinder gas density leads to a consequent decrease of the temperatures along the late diffusive combustion stage $\left(\mathrm{T}_{\text {ad__80 }}\right.$ MBF$\left._{\text {MF }}\right)$, resulting in worsened soot oxidation process and higher final soot emissions.

- The final soot level is determined not only by the combustion temperature at the late-combustion phase but also by the mixing conditions at this late diffusion stage, being both crucial for the late soot oxidation process. A higher delivered trapped mass provides a higher in-cylinder density, enhancing the mixing 
process and shortening the combustion duration, for which final soot emissions are largely reduced.

- The air management conditions are critical to achieve the proper in-cylinder conditions which provide suitable combustion environment to attain high combustion efficiencies and competitive indicated fuel consumption. After the optimization process, it was possible to minimize simultaneously $\mathrm{NO}_{\mathrm{X}}$, soot and indicated fuel consumption, without the existence of a trade-off between the pollutant emissions and the fuel consumption.

- The methodology designed in this research was successfully implemented to optimize the fuel consumption and emissions levels of a 2-stroke engine at the reported engine operating condition. The straight and general relations obtained after the analysis of the results confirm how the best approach for understanding the physical processes linked to 2-stroke engines, is to switch from particular engine operation settings to the final in-cylinder gas thermodynamic conditions, which later controls the combustion process development and final emissions level and efficiency. Thus, this methodology can be extrapolated to design and develop any 2-stroke engine, regardless of its particular architecture or displacement.

Finally, the results obtained along this first stage of evaluation, proved how it is possible to reach and improve the performance of an equivalent 4-stroke engine with a 2 -stroke poppet valves engine. The main trends and relations identified along this research are useful to prepare the path towards future optimization of this particular engine concept to comply with more stringent regulations such as EU6. 


\section{References}

[1] T. Ryan, T. Callahan, Homogeneous charge compression ignition of Diesel fuel, SAE Paper 961160 (1996).

[2] S. Kimura, H. Ogawa, Y. Matsui, Y. Enomoto, An experimental analysis of lowtemperature and premixed combustion for simultaneous reduction of $\mathrm{NO}_{\mathrm{X}}$ and particulate emissions in direct injection Diesel engines, International Journal of Engine Research 3, (2002) 249-259.

[3] R. Kiplimo, E. Tomita, N. Kawahara, S. Yokobe, Effects of spray impingement, injection parameters, and EGR on the combustion and emission characteristics of a PCCI diesel engine, Applied Thermal Engineering 37 (2012) 165-175.

[4] P. Miles, D. Choi, L. Pickett, I. Singh, N. Henein, B. RempelEwert, H. Yun, R. Reitz, Rate-Limiting Processes in Late-Injection, Low Temperature Diesel Combustion Processes, THIESEL Conference Proceedings (2004).

[5] K. Epping, S. Aceves, R. Bechtold, J. Dec, The potential of HCCI combustion for high efficiency and low emissions, SAE Paper 2002-01-1923 (2002).

[6] Q. Fang, J. Fang, J. Zhuang, Z. Huang, Influences of pilot injection and exhaust gas recirculation (EGR) on combustion and emissions in a HCCI-DI combustion engine, Applied Thermal Engineering 48 (2012) 97-104.

[7] J. Benajes, R. Novella, D. De Lima, N. Quechon, P. Obernesser, The potential of highly premixed combustion for pollutant control in an automotive two-stroke HSDI diesel engine, SAE Paper 2012-01-110 (2012).

[8] J. Benajes, R. Novella, D. De Lima, N. Quechon, P. Obernesser, Implementation of the early injection highly premixed combustion concept in a two-stroke HSDI engine, SIA Diesel Powertrain Congress, Conference Proceedings (2012).

[9] T. Köfer, M. Lamping, H. Rohs, D. Adolph, S. Pischinger, The future power density of HSDI Diesel Engines with lowest engine out emissions- A key element for upcoming $\mathrm{CO}_{2}$ demands, Fisita 2008-06-015 (2008).

[10] T. Körfer, M. Lamping, A. Kolbeck, S. Pischinger, D. Adolph, H. Busch, Potential of Modern Diesel Engines with Lowest Raw Emissions - a Key Factor for Future $\mathrm{CO}_{2}$ reduction, SAE Paper 2009-26-0025 (2009).

[11] M. Thirouard, P. Pacaud, Increasing Power Density in HSDI Engines as an Approach for Engine Downsizing, SAE Paper 2010-01-1472 (2010).

[12] J. McCartney, R. Day, A. Ward, C. Rouaud, P. Newman, J. Borges, Y. Baubet, S. Lindsey, Integrated Technologies for Cost Effective $\mathrm{CO}_{2}$ Reduction, SIA Diesel Powertrain Congress, Conference Proceedings (2012).

[13] A. Lefebvre, S. Guilain, Study of different boosting technologies and their effect on the transient response of a very downsized Diesel engine, SIA Diesel Powertrain Congress, Conference Proceedings (2012).

[14] M. Thirouard, S. Mendez, P. Pacaud, V. Chmielarczyk, D. Ambrazas, C. Garsi, F. Lavoisier, B. Barbeau, Potential to Improve Specific Power Using Very High Injection Pressure in HSDI Diesel Engines, SAE Paper 2009-01-1524 (2009).

[15] H. Ecker, M. Schwaderlapp, D. Gill, Downsizing of Diesel Engines: 3-Cylinder / 4Cylinder, SAE Paper 2000-01-0990 (2000).

[16] S. Brandl, B. Graf, A. Rust, NVH Challenges and Solutions for Vehicles with Low CO2 Emission, SAE Int. J. Passeng. Cars - Mech. Syst. 5 (2012) 1084-1090

[17] P. Tribotte, F. Ravet, V. Dugue, P. Obernesser, N. Quechon, J. Benajes, R. Novella, D. De Lima, Two stroke Diesel engine. Promising solution to reduce $\mathrm{CO} 2$ emissions, Procedia - Social and Behavioral Sciences 48 (2012) 2295-2314.

[18] L. Pohorelsky, P. Brynych, J. Macek, P. Vallaude, J. Ricaud , P. Obernesser, P. Tribotte, Air System Conception for a Downsized Two-Stroke Diesel Engine, SAE Paper 2012-01-083 (2012). 
[19] J. Heywood, E. Sher, The two stroke cycle engine: its development, operation and design, SAE International, Taylor and Francis, Warrendale, Pennsylvania, 1999.

[20] G. Blair, The basic design of two-stroke engines, SAE International, Warrendale, Pennsylvania, 1990.

[21] R. Payri, F. Salvador, J. Gimeno, G. Bracho, A new methodology for correcting the signal cumulative phenomenon on injection rate measurements, Experimental Techniques 32 (2008) 46-49.

[22] R. Payri, J. Garcia, F. Salvador, J. Gimeno, Using spray momentum flux measurements to understand the influence of diesel nozzle geometry on spray characteristics, Fuel 84 (2005) 551-561.

[23] D. Olsen, G. Hutcherson, B. Wilson, C. Mitchell, Development of the Tracer Gas Method for Large Bore Natural Gas Engines: Part 1 - Method Validation, Journal of Engineering for Gas Turbines and Power 124 Issue 3 (2002) 678-685.

[24] D. Olsen, G. Hutcherson, B. Wilson, C. Mitchell, Development of the Tracer Gas Method for Large Bore Natural Gas Engines: Part 2 - Measurement of Scavenging Parameters, Journal of Engineering for Gas Turbines and Power 124 Issue 3 (2002) 686-694.

[25] M. Lapuerta, O. Armas, J. Hernández, Diagnostic of D.I. Diesel Combustion from InCylinder Pressure Signal by Estimation of Mean Thermodynamic Properties of the Gas, Applied Thermal Engineering 19 (1999) 513-529.

[26] F. Payri, S. Molina, J. Martín, O. Armas, Influence of measurement errors and estimated parameters on combustion diagnosis, Applied Thermal Engineering 26 (2-3) (2006) 226-236.

[27] R. Way, Methods for determination of composition and thermodynamic properties of combustion products for internal combustion engine calculations, Proceedings of the Institution of Mechanical Engineers 190 (1976) 686-97.

[28] J. Dec, R. Canaan, PLIF imaging of NO formation in a DI diesel engine, SAE Paper 980147 (1998).

[29] Y. Kitamura, A. Mohammadi, T. Ishiyama, M. Shioji, Fundamental Investigation of $\mathrm{NO}_{\mathrm{X}}$ Formation in Diesel Combustion Under Supercharged and EGR Conditions, SAE Paper 2005-01-0364 (2005).

[30] J. Dec, A conceptual model of DI Diesel combustion based on laser-sheet imaging, SAE Paper 970873 (1997).

[31] D. Tree, K. Svensson, Soot processes in compression ignition engines, Progress in Energy and Combustion 33 (2007) 272-309.

[32] J. Benajes, R. Novella, A. García, S. Arthozoul, The role of in-cylinder gas density and oxygen concentration on late spray mixing and soot oxidation processes, Energy 36 (2011) 1599-1611.

[33] J. Benajes, R. Novella, S. Arthozoul, C. Kolodziej, Particle Size Distribution Measurements from Early to Late Injection Timing Low Temperature Combustion in a Heavy Duty Diesel Engine, SAE Paper 2010-01-1121 (2010).

[34] F. Payri, J. Benajes, R. Novella, C. Kolodziej, Effect of Intake Oxygen Concentration on Particle Size Distribution Measurements from Diesel Low Temperature Combustion, SAE Paper 2011-01-1355 (2011).

[35] J. Benajes, J. García, R. Novella , C. Kolodziej, Increased particle emissions from early fuel injection timing Diesel low temperature combustion, Fuel 94 (2012) 184-190.

[36] J. Arregle, J. López, J. García, C. Fenellosa, Development of a zero-dimensional Diesel combustion model. Part 1: analysis of the quasi-steady diffusion combustion phase, Applied Thermal Engineering 23 (2003) 1301-1317.

[37] K. De Rudder, An approach to low-temperature combustion in a small HSDI engine, $\mathrm{PhD}$ Thesis, Universitat Politècnica de València, Valencia, Spain, 2007. 


\section{ACKNOWLEDGMENTS}

This research has been sponsored by the European Union in framework of the POWERFUL project, seventh framework program FP7/2007-2013, theme 7, sustainable surface transport, grant agreement No. SCP8-GA-2009-234032. The authors gratefully appreciate this support.

\section{Nomenclature}

\begin{tabular}{|c|c|}
\hline aTDC & After Top Dead Centre \\
\hline $\mathrm{ACT}^{-1} 80 \% \mathrm{MBF}$ & Gas mixing capacity at $80 \%$ of the mass burnt fraction \\
\hline$(\mathrm{A} / \mathbf{F})_{\mathrm{st}}$ & Stoichiometric Air to Fuel ratio \\
\hline$\alpha_{i}$ and $\beta_{i}$ & Adjustment coefficients of the Merit Function \\
\hline BDC & Bottom Dead Centre \\
\hline CA50 & Crank angle for $50 \%$ of fuel burnt \\
\hline CA90 & Crank angle for $90 \%$ of fuel burnt \\
\hline cad & Crank angle degree \\
\hline CFD & Computational Fluid Dynamics \\
\hline DOE & Design of experiments \\
\hline$\Delta \mathbf{P}$ & Pressure drop between the intake and the exhaust \\
\hline $\mathrm{dP} / \mathrm{d} \alpha$ & Maximum pressure gradient \\
\hline EGR & Exhaust Gas Recirculation \\
\hline EU5, EU6 & European emissions standards \\
\hline HCCI & Homogeneous Charge Compression Ignition \\
\hline HSDI & High Speed Direct Injection \\
\hline IGR & Internal Gas Recirculation \\
\hline IMEP & Indicated Mean Effective Pressure \\
\hline isfe & Indicated specific fuel consumption \\
\hline isfe $_{\text {corr }}$ & Corrected indicated specific fuel consumption \\
\hline IVC & Intake Valve Closing (angle) \\
\hline K1 & Proportionally constant depending on engine configuration \\
\hline LTC & Low Temperature Combustion \\
\hline MBF & Mass burnt fraction \\
\hline MF & Merit function \\
\hline NVH & Noise, Vibrations and Harshness \\
\hline $\mathbf{O V}$ & Objective/target value of the response \\
\hline PCCI & Premixed Charge Compression Ignition \\
\hline$\phi_{-}$cyl_eff & Effective in-cylinder equivalence ratio \\
\hline$\phi_{0}$ & Injector nozzle diameter \\
\hline $\mathbf{Q}_{\text {delivered }}$ & Total delivered flow rate (fresh air flow + EGR) \\
\hline$Q_{\text {del_trapped }}$ & Fraction of the delivered flow which is actually retained in the cylinder \\
\hline $\mathbf{R V}$ & Response value \\
\hline RoHR & Rate of Heat Release \\
\hline $\mathbf{R}^{2}$ & Correlation coefficient between the estimated vs. the measured responses \\
\hline$\rho$ & In-cylinder gas density \\
\hline$\rho_{\mathrm{f}}$ & Fuel density \\
\hline SoI & Start Of Injection \\
\hline $\mathbf{T}_{\text {ad_max }}$ & Maximum adiabatic flame temperature \\
\hline $\mathbf{T}_{\text {ad_80\%MBF }}$ & Adiabatic flame temperature at the $80 \%$ of fuel mass burnt fraction \\
\hline $\mathbf{t}_{\text {mix }}$ & Characteristic mixing time \\
\hline TDC & Top Dead Centre \\
\hline $\mathbf{T}_{\text {SoI,pilot }}$ & Gas temperature at the start of injection of the pilot injection \\
\hline VVT & Variable Valve Timing \\
\hline $\mathrm{YO}_{2}$ & Oxygen concentration in the cylinder \\
\hline $\mathrm{YO}_{2}$ atm & Atmospheric oxygen concentration \\
\hline $\mathrm{YO}_{2} \mathrm{IVC}$ & Oxygen concentration at the intake valve closing angle \\
\hline
\end{tabular}




\section{List of Figures}

1. Sketch of the cylinder head designed for the 2-stroke engine architecture (Patent Renault FR2931880)

2. Lift vs crank angle for intake and exhaust valves.

3. Layout of the engine test cell

4. Air management characteristics. a) $\Delta \mathrm{P}$ and b) Overlap as function of trapping ratio and delivered mass flow rate

5. Air management characteristics. a) $\mathrm{YO}_{2}$ at the IVC and b) effective in-cylinder equivalence ratio as function of trapping ratio and delivered mass flow rate

6. Combustion characteristics. a) Ignition delay of the main injection and b) maximum RoHR as function of the $\mathrm{YO}_{2}$ IVC and the gas temperature at the SoI of the pilot injection

7. Combustion characteristics. a) Maximum pressure gradient and b) noise as function of the $\mathrm{YO}_{2}$ IVC and the gas temperature at the SoI of the pilot injection

8. Combustion characteristics. a) Maximum adiabatic flame temperature and b) adiabatic temperature at $80 \%$ of $\mathrm{MBF}$ as a function of $\mathrm{YO}_{2} \mathrm{IVC}$ and effective in-cylinder equivalence ratio

9. Combustion characteristics. a) Mixing capacity as a function of the $\mathrm{YO}_{2}$ IVC and the effective in-cylinder equivalence ratio. b) Mixing capacity as a function of delivered trapped mass flow and CA90

10. Exhaust emissions and performance. a) $\mathrm{CO}$ and b) $\mathrm{HC}$ as function of smoke and $\mathrm{NO}_{\mathrm{X}}$ emissions

11. Exhaust emissions and performance. a) Maximum adiabatic flame temperature and b) adiabatic flame temperature at $80 \%$ of $\mathrm{MBF}$ as function of smoke and $\mathrm{NO}_{\mathrm{X}}$ emissions

12. Exhaust emissions and performance. Mixing capacity as a function of smoke and $\mathrm{NO}_{\mathrm{X}}$ emissions

13. Exhaust emissions and performance. a) isfc and b) isfecorr as a function of smoke and $\mathrm{NO}_{\mathrm{X}}$ emissions

14. Optimization of the DOE. a) Merit function based on $\mathrm{NO}_{\mathrm{X}}$, smoke and isfc. b) Merit function based on $\mathrm{NO}_{\mathrm{X}}$, smoke and isfec $\mathrm{corr}_{\mathrm{c}}$ 


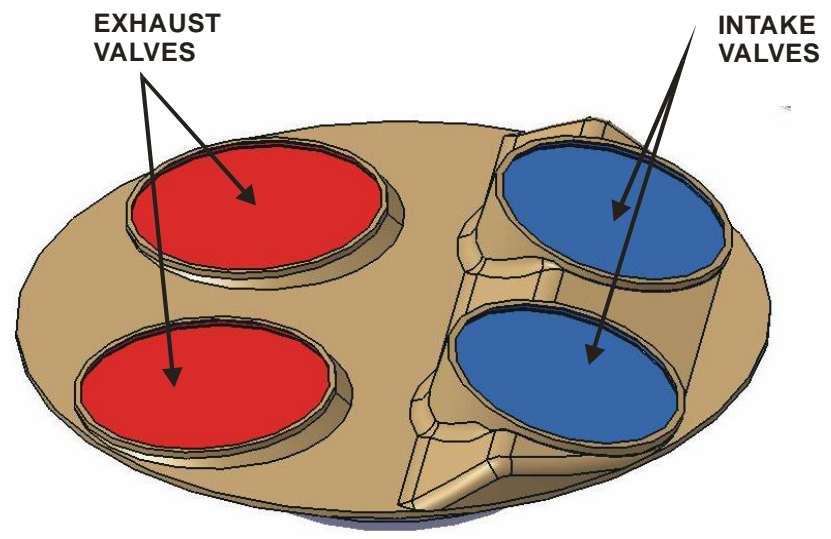

Fig. 1: Sketch of the cylinder head designed for the 2-stroke engine architecture (Patent Renault FR2931880). 
Paper draft:

Analysis of the combustion process, pollutant emissions and performance of an innovative 2-stroke HSDI engine designed for automotive applications

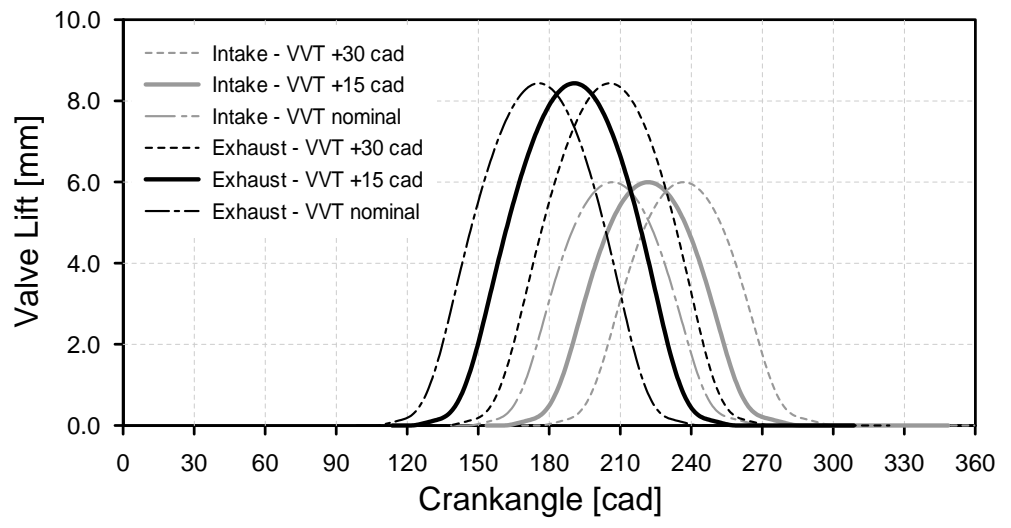

Fig. 2: Lift vs crank angle for intake and exhaust valves. 
Paper draft:

Analysis of the combustion process, pollutant emissions and performance of an innovative 2-stroke HSDI engine designed for automotive applications

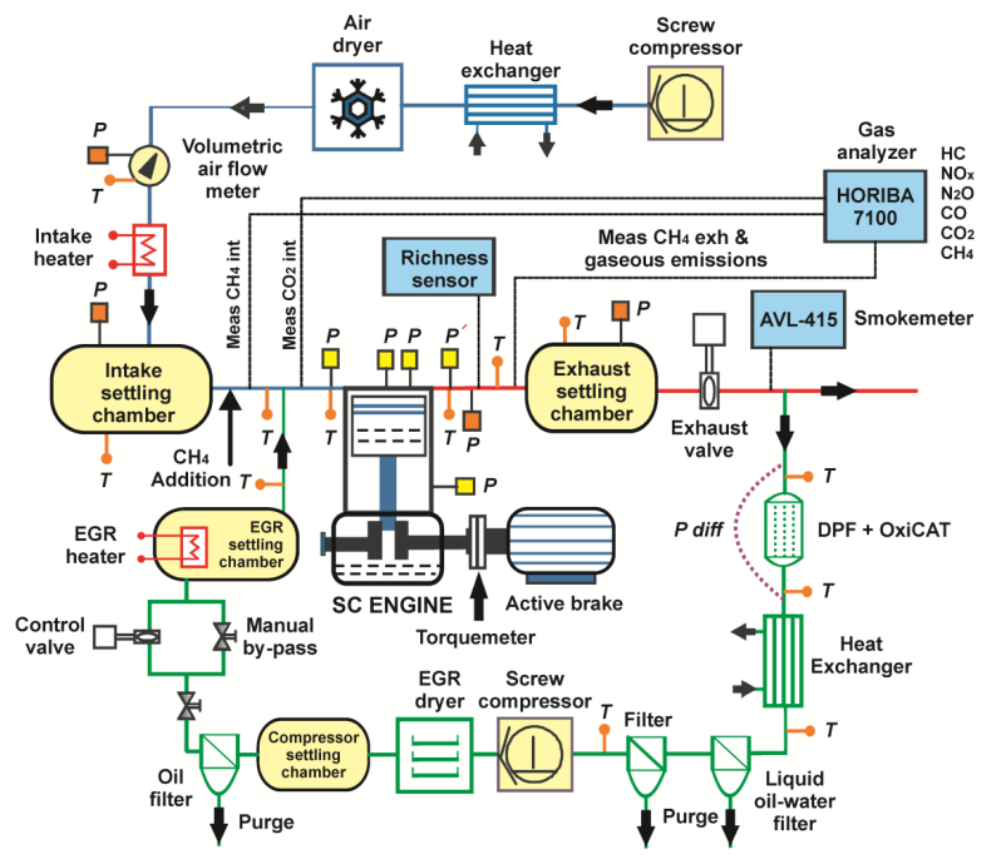

Fig. 3: Layout of the engine test cell. 

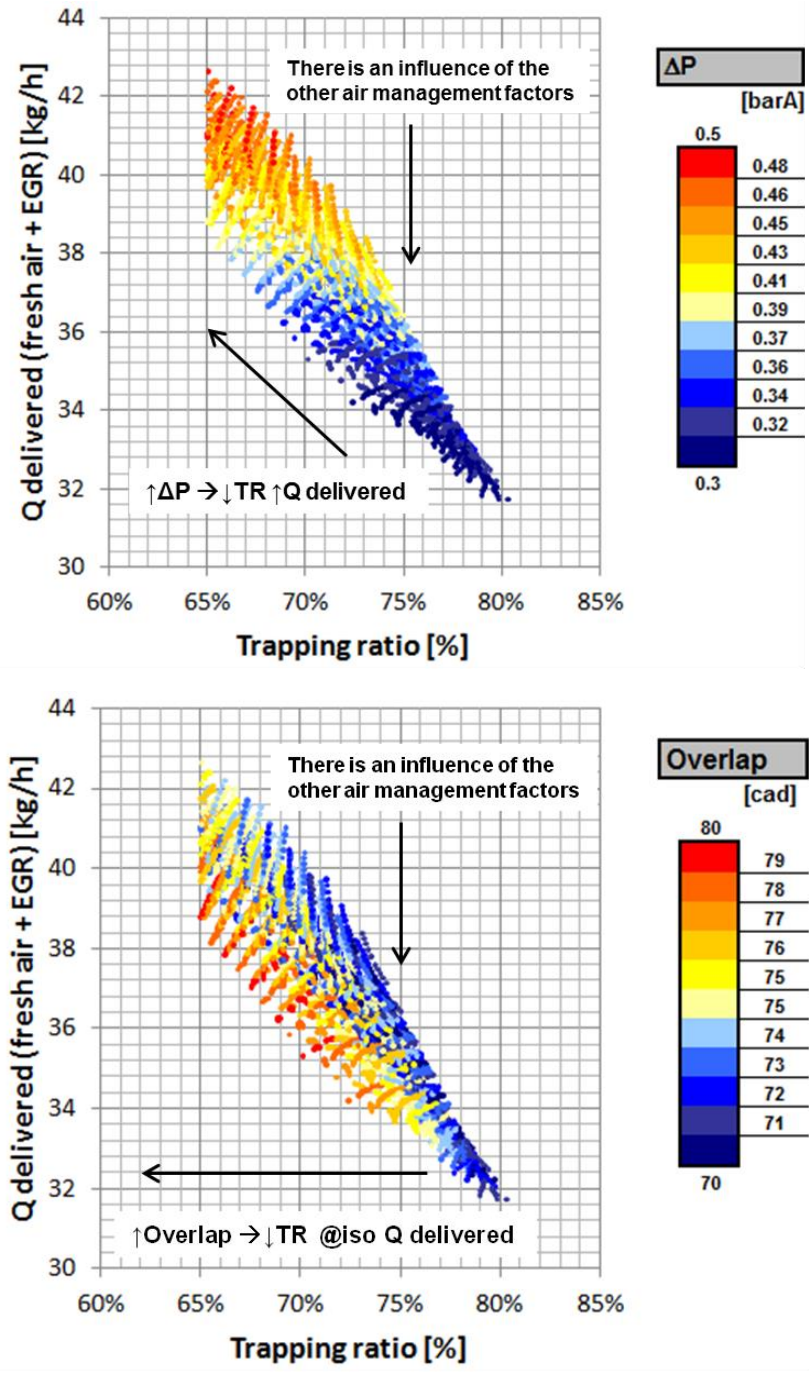

Fig. 4: Air management characteristics. a) $\Delta \mathrm{P}$ and b) Overlap as function of trapping ratio and delivered mass flow rate. 

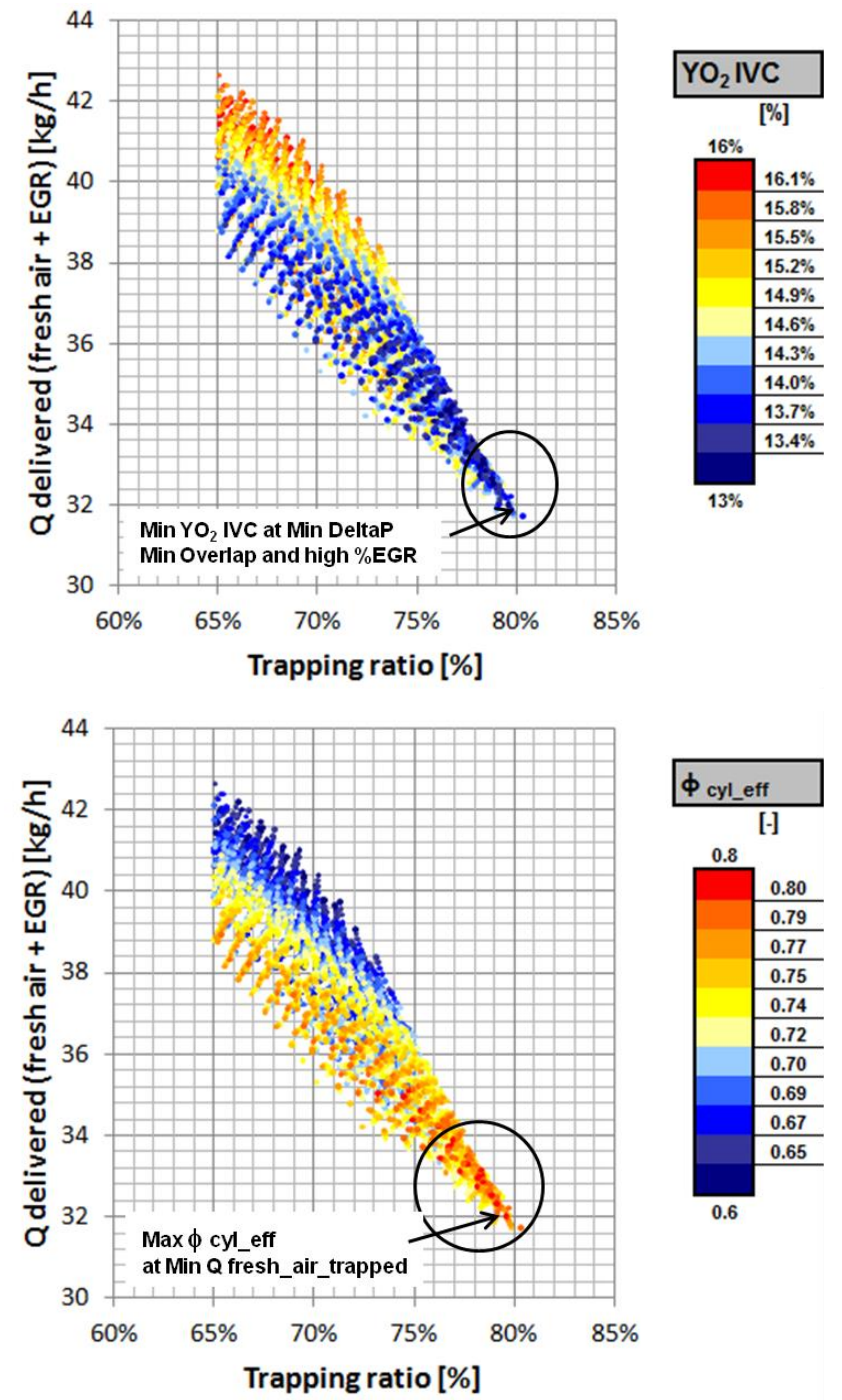

Fig. 5: Air management characteristics. a) $\mathrm{YO}_{2}$ at the IVC and b) effective in-cylinder equivalence ratio as function of trapping ratio and delivered mass flow rate. 

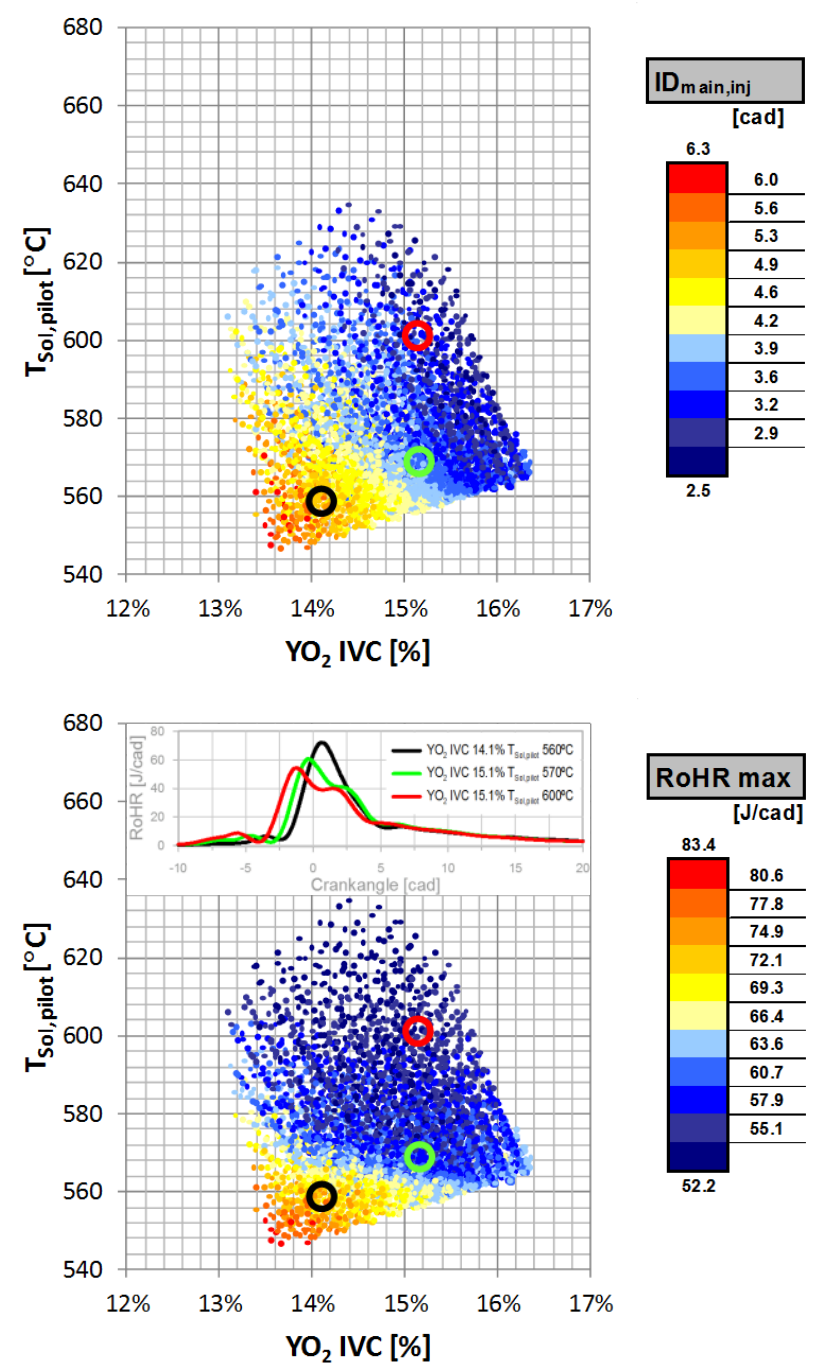

Fig. 6: Combustion characteristics. a) Ignition delay of the main injection and b) maximum RoHR as function of the $\mathrm{YO}_{2}$ IVC and the gas temperature at the SoI of the pilot injection. 

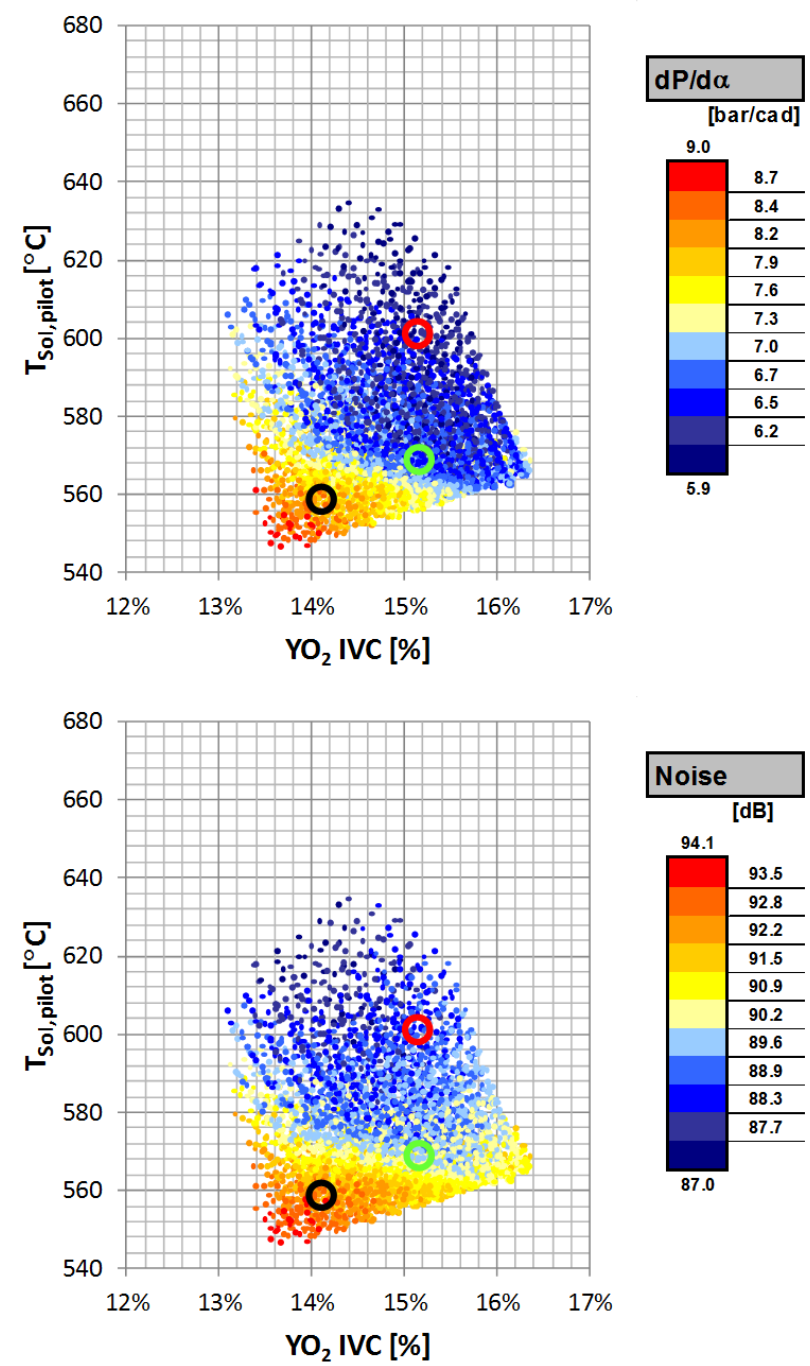

Fig. 7: Combustion characteristics. a) Maximum pressure gradient and b) noise as function of the $\mathrm{YO}_{2} \mathrm{IVC}$ and the gas temperature at the SoI of the pilot injection. 

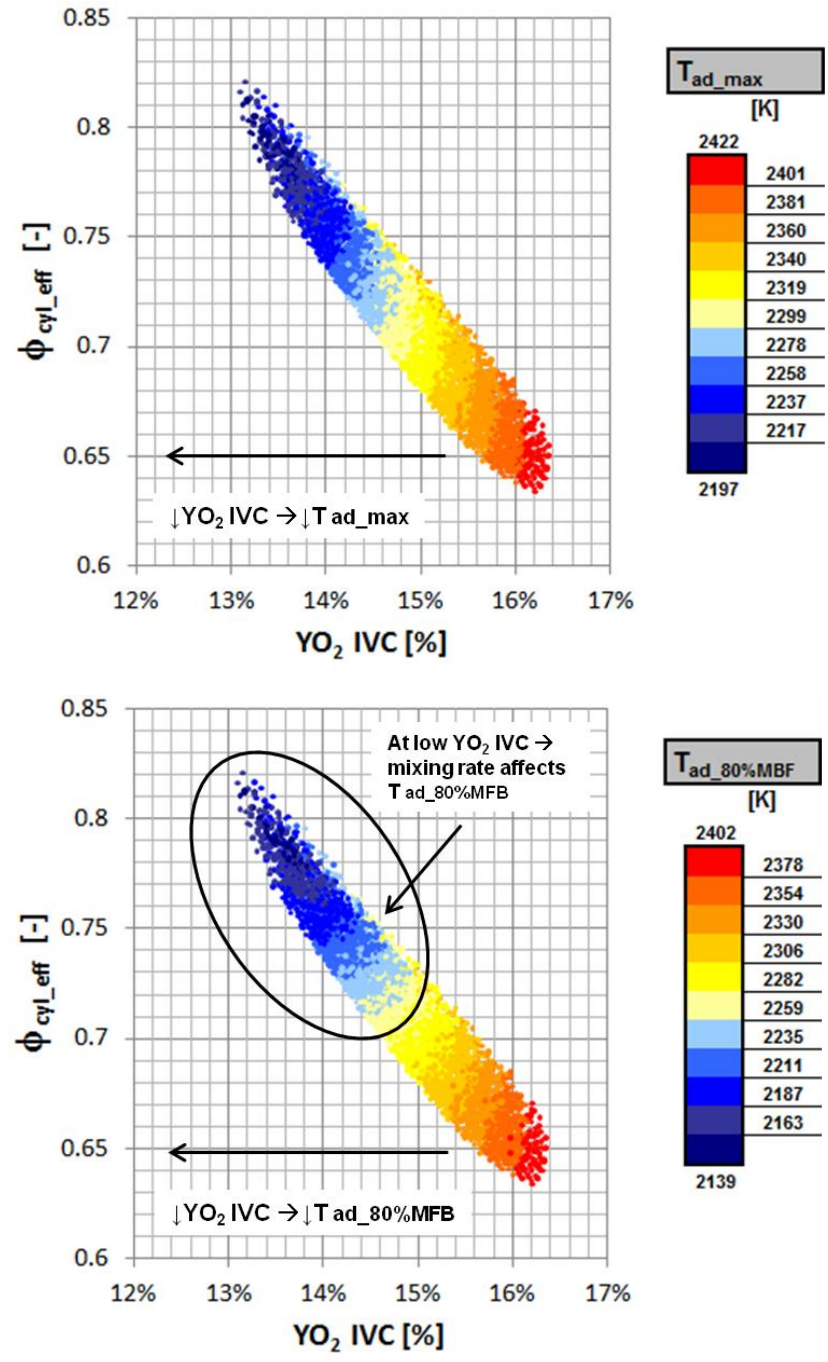

Fig. 8: Combustion characteristics. a) Maximum adiabatic flame temperature and b) adiabatic temperature at $80 \%$ of MBF as a function of $\mathrm{YO}_{2}$ IVC and effective incylinder equivalence ratio 

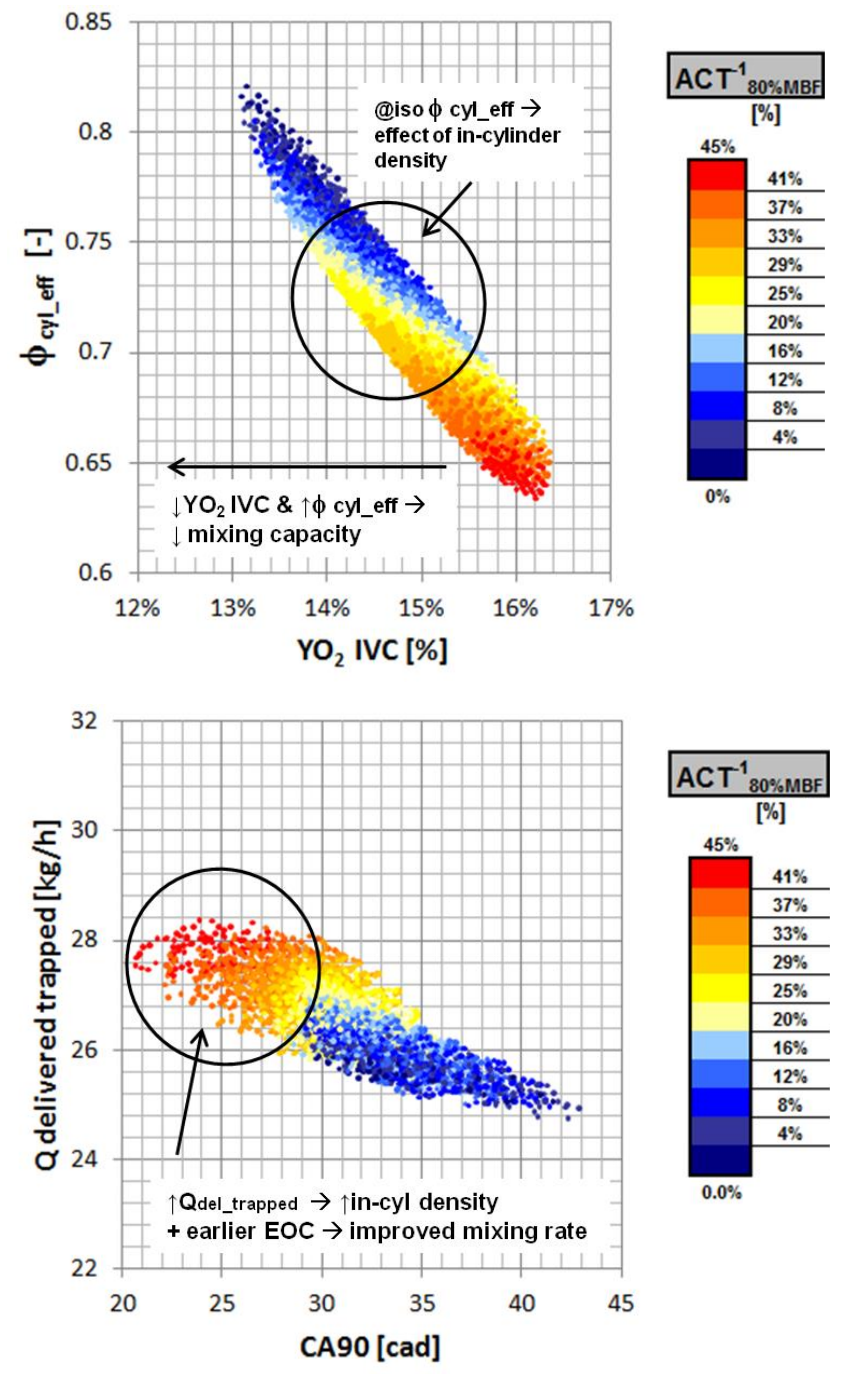

Fig. 9: Combustion characteristics. a) Mixing capacity as a function of the $\mathrm{YO}_{2}$ IVC and the effective in-cylinder equivalence ratio. b) Mixing capacity as a function of delivered trapped mass flow and CA90 

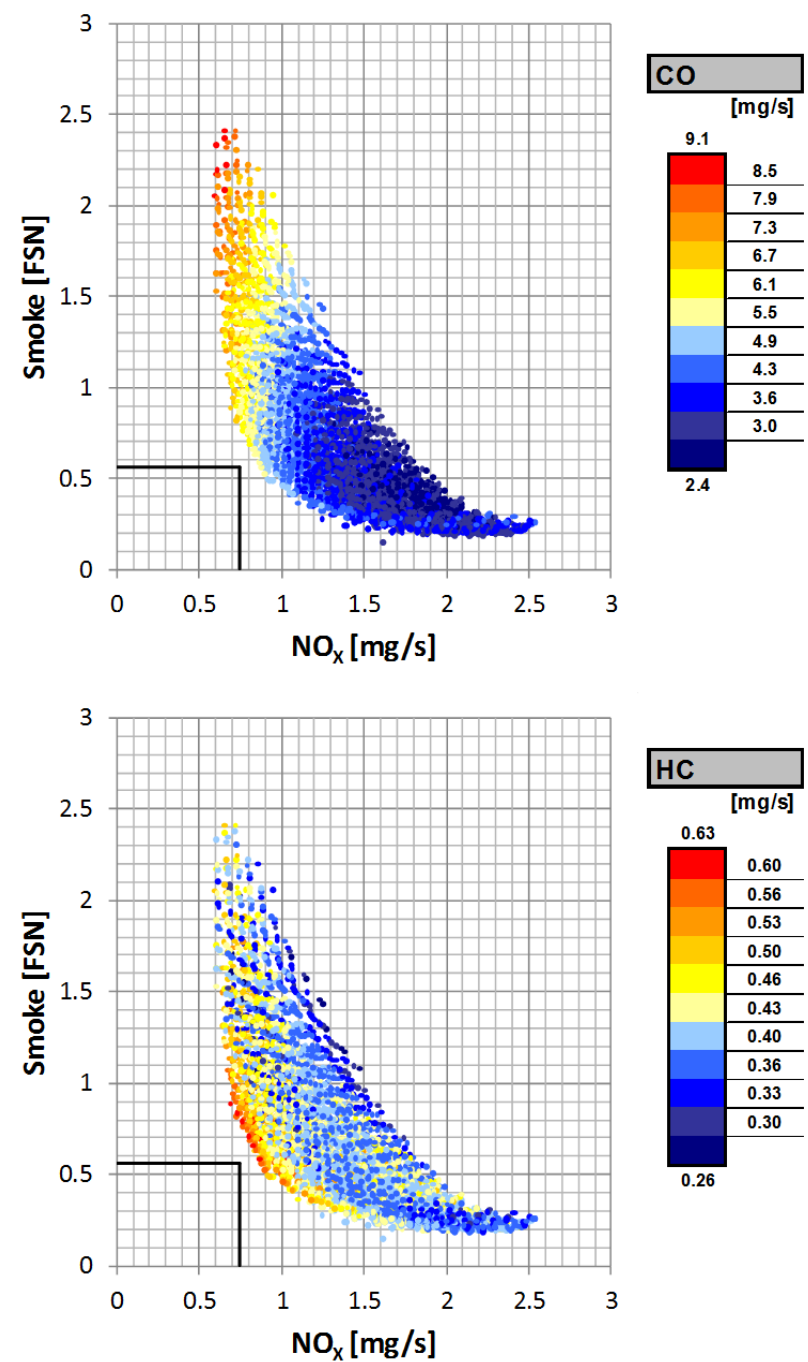

Fig. 10: Exhaust emissions and performance. a) $\mathrm{CO}$ and b) $\mathrm{HC}$ as function of smoke and $\mathrm{NO}_{\mathrm{X}}$ emissions 

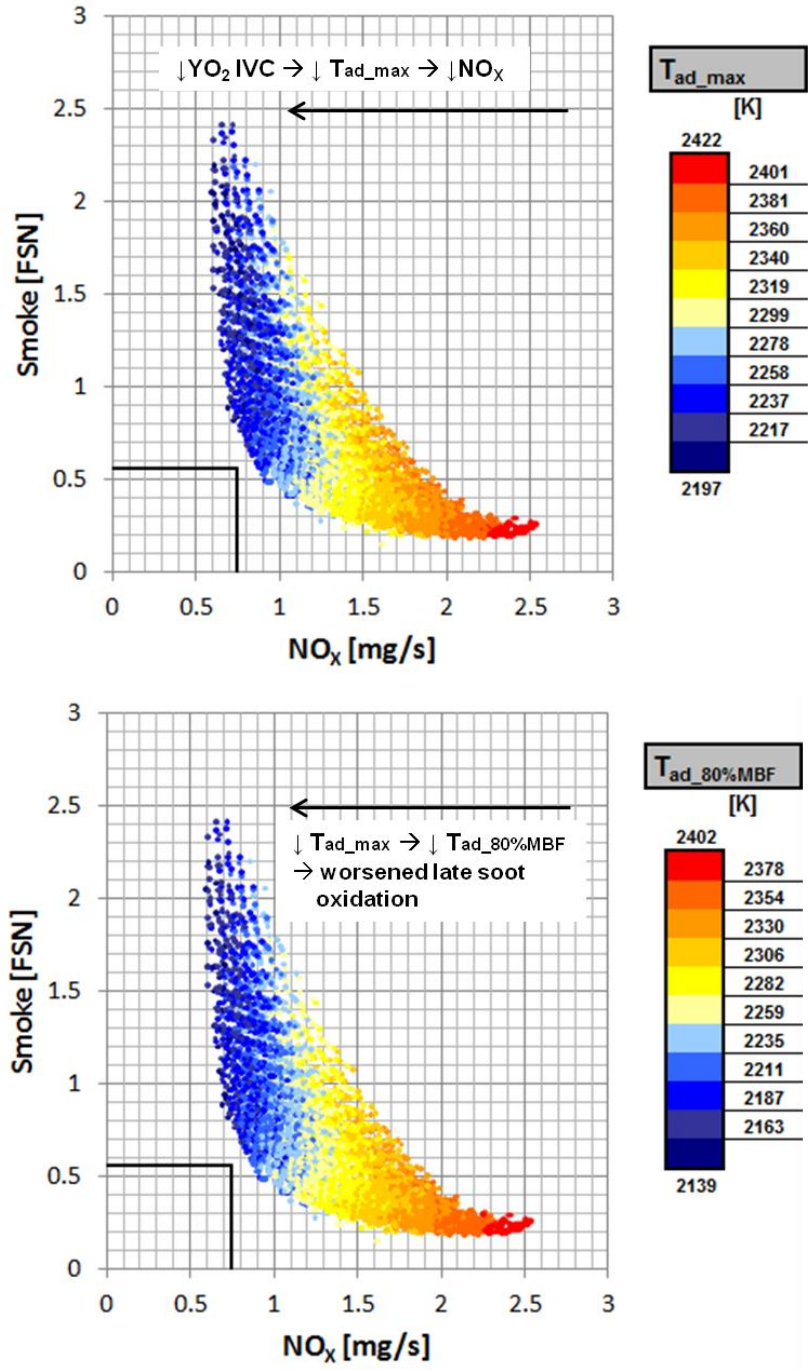

Fig. 11: Exhaust emissions and performance. a) Maximum adiabatic flame temperature and b) adiabatic flame temperature at $80 \%$ of the $\mathrm{MBF}$ as function of smoke and $\mathrm{NO}_{\mathrm{X}}$ emissions 


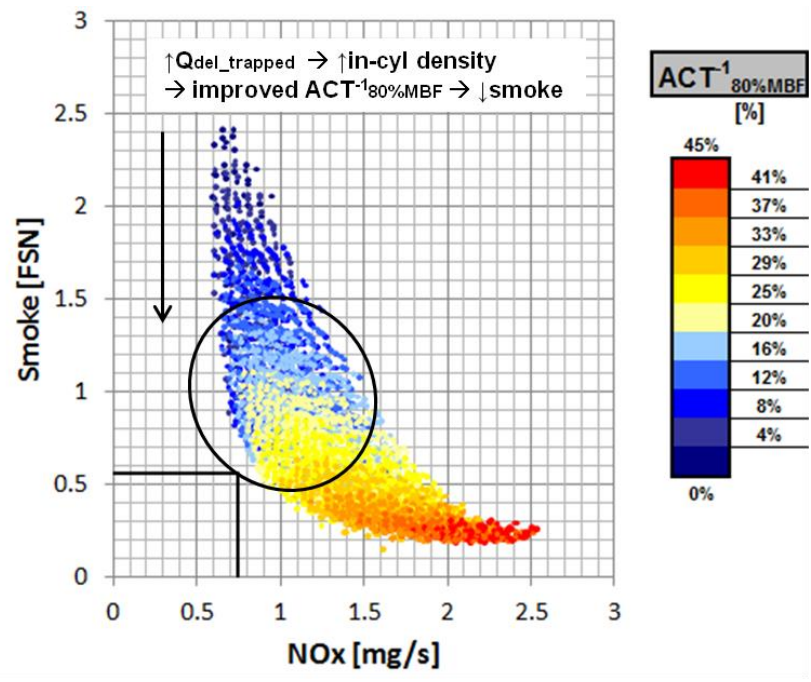

Fig. 12: Exhaust emissions and performance. Mixing capacity as a function of smoke and $\mathrm{NO}_{\mathrm{X}}$ emissions 

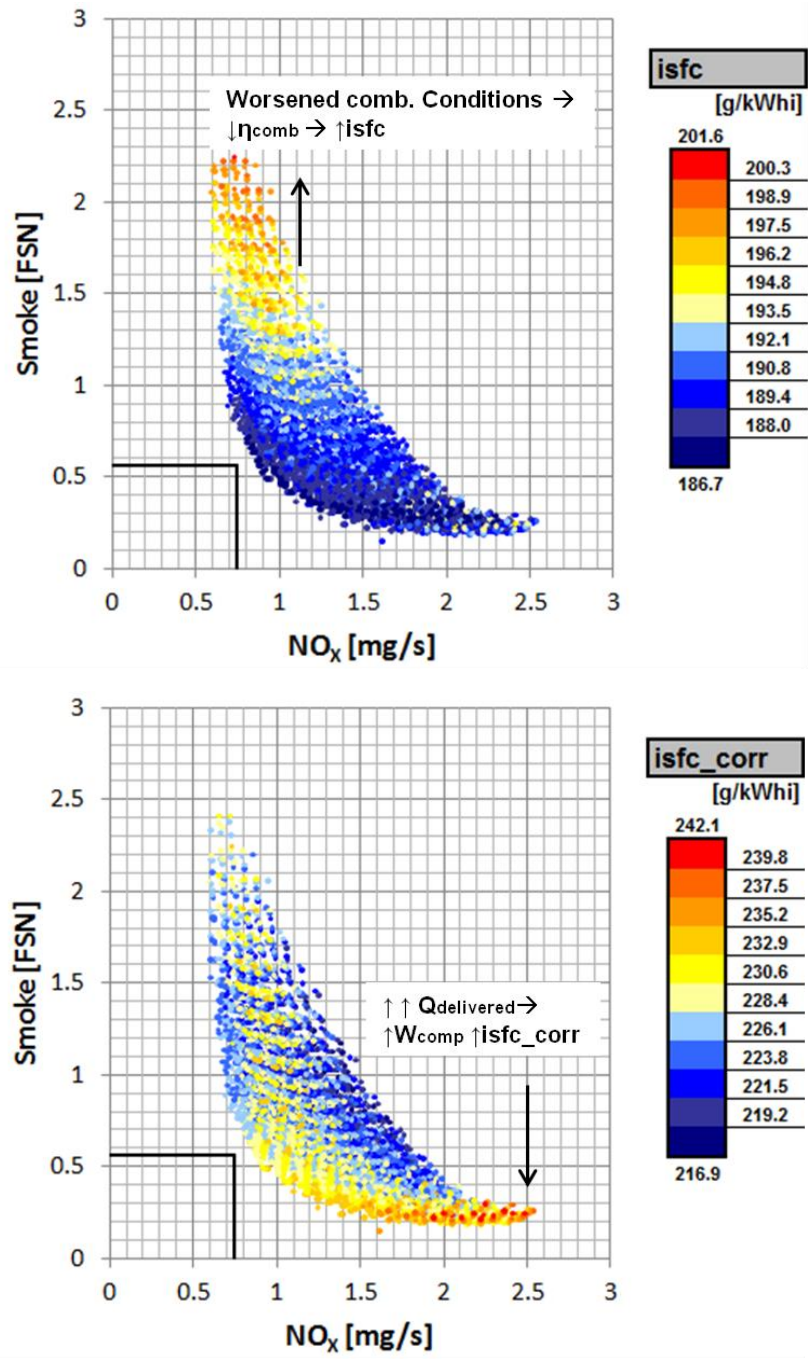

Fig. 13: Exhaust emissions and performance. a) isfc and b) isfc corr $_{\text {as a function of }}$ smoke and $\mathrm{NO}_{\mathrm{X}}$ emissions 

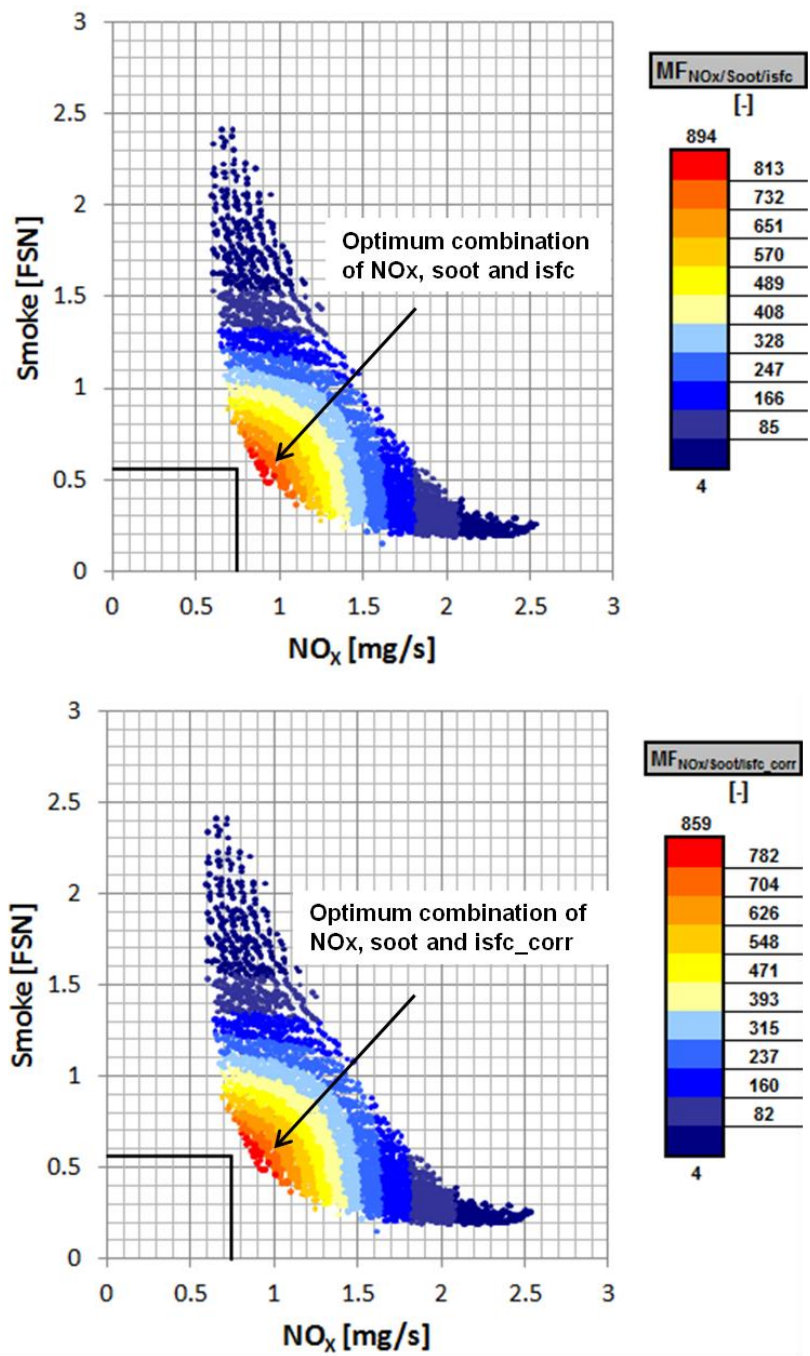

Fig. 14: Optimization of the DOE. a) Merit function based on $\mathrm{NO}_{\mathrm{X}}$, smoke and isfc. b) Merit function based on $\mathrm{NO}_{\mathrm{X}}$, smoke and isfec $\mathrm{corr}$ 


\section{List of Tables}

1. Main engine geometrical characteristics 38

2. Experimental test conditions and emissions and noise limits

3. Air management related parameters included in the DOE, and their ranges of variation

4. Statistical analysis of the most important responses

5. Validation of the statistical models at two different optimum points

6. Measured responses at optimum point \#2 
Table 1: Main engine geometrical characteristics.

\begin{tabular}{|l|l|}
\hline Displacement & $365 \mathrm{~cm}^{3}$ \\
\hline Bore & $76 \mathrm{~mm}$ \\
\hline Stroke & $80.5 \mathrm{~mm}$ \\
\hline Connecting rod length & $133.75 \mathrm{~mm}$ \\
\hline Geometric CR & 17.8 \\
\hline Number of valves/cylinder & 4 \\
\hline Type of scavenge & Poppet valves with scavenge loop \\
\hline Intake camshaft profile & Duration: $80 \mathrm{cad} /$ Max. Lift: $6 \mathrm{~mm}$ \\
\hline Exhaust camshaft definition & Duration: $95 \mathrm{cad} /$ Max. Lift: $8.5 \mathrm{~mm}$ \\
\hline
\end{tabular}


Table 2: Experimental test conditions and emissions and noise limits.

\begin{tabular}{|l|l|}
\hline Engine speed & $1500 \mathrm{rpm}$ \\
\hline IMEP & $5.5 \mathrm{bar}$ \\
\hline Injection Pressure & $900 \mathrm{bar}$ \\
\hline SoI pilot injection & $-19 \mathrm{cad}$ aTDC \\
\hline SoI main injection ** (adjusted) & $-9 \mathrm{cad}$ aTDC \\
\hline IVC / VVT position & $259.7 \mathrm{cad} /(+13)$ \\
\hline $\begin{array}{l}\text { EVC / VVT position } \\
\text { (range of variation given by overlap) }\end{array}$ & $\begin{array}{l}\text { From } 240.4 \text { to } 250.4 \mathrm{cad} / \\
\text { (from }+18 \text { to }+28)\end{array}$ \\
\hline Intake air temperature & $35^{\circ} \mathrm{C}$ \\
\hline Coolant and oil temperature & $90^{\circ} \mathrm{C}$ \\
\hline NOX limit & $0.75 \mathrm{mg} / \mathrm{s}$ \\
\hline HC limit & $0.65 \mathrm{mg} / \mathrm{s}$ \\
\hline CO limit & $4.4 \mathrm{mg} / \mathrm{s}$ \\
\hline Soot limit & $0.56 \mathrm{FSN}$ \\
\hline Noise limit & $89.9 \mathrm{~dB}$ \\
\hline
\end{tabular}


Table 3: Air management related parameters included in the DOE, and their ranges of variation.

\begin{tabular}{|l|c|c|}
\hline Air management factor & From & To \\
\hline EGR Rate [\%] & 26 & 36 \\
\hline Intake Pressure [bar] & 1.6 & 1.7 \\
\hline$\Delta$ P [bar] & 0.3 & 0.5 \\
\hline Overlap [cad] & 70 & 80 \\
\hline
\end{tabular}


Table 4: Statistical analysis of the most important responses.

\begin{tabular}{|l|l|l|l|}
\hline \multicolumn{1}{|c|}{ Measured/modeled responses } & $\mathbf{R}^{2}[-]$ & $\begin{array}{c}\text { Standard } \\
\text { deviation } \\
\text { of Error }\end{array}$ & $\begin{array}{c}\text { Mean } \\
\text { absolute } \\
\text { Error }\end{array}$ \\
\hline Trapping ratio [\%] & 0.9899 & 0.2095 & 0.2712 \\
\hline Delivered fresh air [kg/h] & 0.9975 & 0.0815 & 0.0858 \\
\hline Effective In-cylinder richness [-] & 0.9697 & 0.0030 & 0.0041 \\
\hline Oxygen concentration at IVC [\%] & 0.9838 & 0.0394 & 0.0551 \\
\hline Max adiabatic flame temperature [K] & 0.9689 & 4.4726 & 4.9189 \\
\hline Adiabatic flame temperature at 80\%MBF [K] & 0.9708 & 4.5702 & 5.6412 \\
\hline Gas mixing capacity (ACT ${ }^{-1}$ ) at 80\%MFB [A.U] & 0.9539 & 0.0093 & 0.0117 \\
\hline NO ${ }_{X}$ emissions [mg/s] & 0.9969 & 0.0121 & 0.0135 \\
\hline Soot emissions [FSN] & 0.9894 & 0.0206 & 0.0273 \\
\hline Indicated specific fuel consumption [g/kWh] & 0.9354 & 0.2442 & 0.3374 \\
\hline Corrected indicated specific fuel consumption [g/kWh] & 0.9742 & 0.3576 & 0.4486 \\
\hline
\end{tabular}


Table 5: Validation of the statistical models at two different optimum points.

\begin{tabular}{|l|c|c|}
\cline { 2 - 3 } \multicolumn{1}{c|}{} & \multicolumn{2}{c|}{$\begin{array}{c}\text { Error between } \\
\text { Modeled/Measured }\end{array}$} \\
\hline Measured/modeled responses & Opt \#1 & Opt \#2 \\
\hline Trapping ratio [\%] & $0.40 \%$ & $1.36 \%$ \\
\hline Delivered fresh air [kg/h] & $0.51 \%$ & $1.05 \%$ \\
\hline $\mathrm{NO}_{\mathrm{X}}$ emissions [mg/s] & $1.12 \%$ & $1.82 \%$ \\
\hline Soot emissions [FSN] & $0.55 \%$ & $4.78 \%$ \\
\hline Indicated specific fuel consumption $[\mathrm{g} / \mathrm{kWh}]$ & $0.35 \%$ & $0.44 \%$ \\
\hline Corrected indicated specific fuel consumption $[\mathrm{g} / \mathrm{kWh}]$ & $1.38 \%$ & $0.82 \%$ \\
\hline
\end{tabular}


Table 6: Measured responses at optimum point \#2.

\begin{tabular}{|l|c|}
\hline \multicolumn{1}{|c|}{ Measured responses } & Optimum \#2 \\
\hline Trapping ratio [\%] & $67.9 \%$ \\
\hline IGR Rate [\%] & $36.4 \%$ \\
\hline Effective in-cylinder equivalence ratio [-] & 0.71 \\
\hline EGR rate [\%] & $35 \%$ \\
\hline $\mathrm{YO}_{2}$ at the IVC [\%] & $14.3 \%$ \\
\hline $\mathrm{NO}_{\mathrm{X}}[\mathrm{mg} / \mathrm{s}]$ & 1.09 \\
\hline $\mathrm{Smoke}[\mathrm{FSN}]$ & 0.43 \\
\hline Combustion efficiency [\%] & $99.4 \%$ \\
\hline Indicated specific fuel consumption [g/kWh] & 187.61 \\
\hline Indicated efficiency [\%] & $45.6 \%$ \\
\hline
\end{tabular}

